
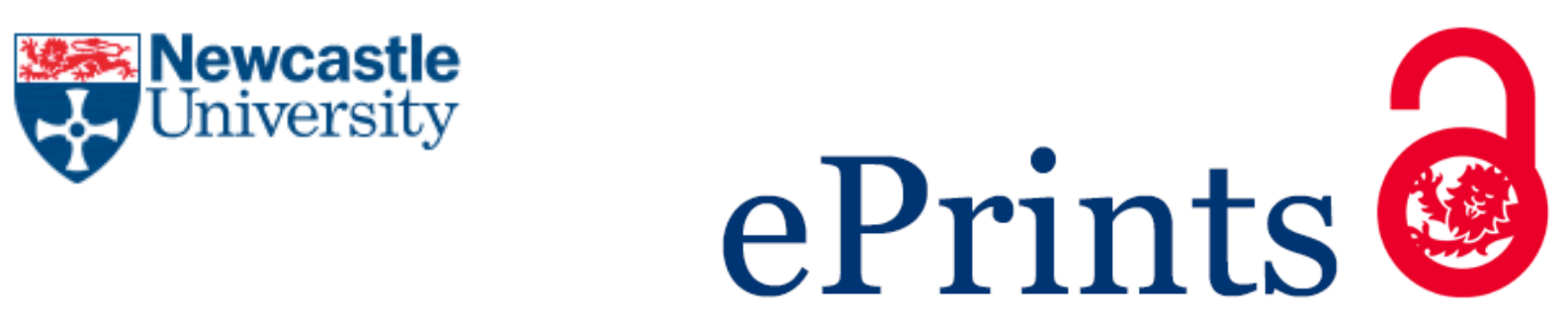

Xing L, Cai Q, Liu X, Liu C, Scott K, Yan Y. Anode partial flooding modelling of proton exchange membrane fuel cells: Optimisation of electrode properties and channel geometries. Chemical Engineering Science 2016, 146, 88-103.

\title{
Copyright:
}

(C) 2016. This manuscript version is made available under the CC-BY-NC-ND 4.0 license

DOI link to article:

http://dx.doi.org/10.1016/i.ces.2016.02.029

Date deposited:

$14 / 03 / 2016$

Embargo release date:

27 February 2017

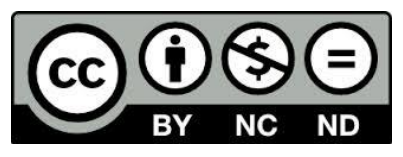

This work is licensed under a

Creative Commons Attribution-NonCommercial-NoDerivatives 4.0 International licence 


\section{Anode partial flooding modelling of proton exchange membrane fuel cells: Optimisation of electrode properties and channel geometries}

Lei Xing ${ }^{\mathrm{a}, \mathrm{b}^{*}}$, Qiong Cai ${ }^{\mathrm{c}}$, Xiaoteng Liu $^{\mathrm{d}}$, Chunbo Liu ${ }^{\mathrm{a}}$, Keith Scott ${ }^{\mathrm{d}}$, Yongsheng Yan ${ }^{\mathrm{a}}$

a. Institute of Green Chemistry and Chemical Technology, Jiangsu University, Zhenjiang, 212013, China

b. School of Chemical Engineering, University of Birmingham, Edgbaston, Birmingham, B15 2TT, United Kingdom

c. Department of Chemical and Process Engineering, University of Surrey, Guildford, GU2 7XH, United Kingdom

d. School of Chemical Engineering and Advanced Materials, Merz Court, Newcastle University, Newcastle upon Tyne,

NE1 7RU, United Kingdom

Corresponding author:

Institute of Green Chemistry and Chemical Technology, Jiangsu University, Zhenjiang, 212013, China Tel./fax: +86 (0)511 88790885

Email: xinglei1314@gmail.com; 1 .xing@bham.ac.uk

Qiong Cai (q.cai@surrey.ac.uk);

Xiaoteng Liu (x.liu@ncl.ac.uk);

Chunbo Liu (liuchunbojsu@163.com);

Keith Scott (k.scott@ncl.ac.uk);

Yongsheng Yan (yys@ujs.edu.cn) 


\section{Abstract}

A two-dimensional, along-the-channel, two-phase flow, non-isothermal model is developed which represents a low temperature proton exchange membrane (PEM) fuel cell. The model describes the liquid water profiles and heat distributions inside the membrane electrode assembly (MEA) and gas flow channels as well as effectiveness factors of the catalyst layers. All the major transport and electrochemical processes are taken into account except for reactant species crossover through the membrane. The catalyst layers are treated as spherical agglomerates with inter-void spaces, which are in turn covered by ionomer and liquid water films. Liquid water formation and transport at the anode is included while water phase-transfer between vapour, dissolved water and liquid water associated with membrane/ionomer water uptake, desorption and condensation/evaporation are considered. The model is validated by experimental data and used to numerically study the effects of electrode properties (contact angel, porosity, thickness and platinum loading) and channel geometries (length and depth) on liquid water profiles and cell performance. Results reveal low liquid water saturation with large contact angle, low electrode porosity and platinum loading, and short and deep channel. An optimal channel length of $1 \mathrm{~cm}$ was found to maximise the current densities at low cell voltages. A novel channel design featured with multi- outlets and inlets along the channel was proposed to mitigate the effect of water flooding and improve the cell performance.

Keywords: Electrode property, channel dimension, anode flooding, two-phase flow, channel design, PEM fuel cell

\section{Introduction}


Proton exchange membrane (PEM) fuel cells are considered as promising candidate in automotive, portable and residential applications benefited from their high efficiency, high volumetric power density and zero emission of greenhouse gases during operation [Wang et al., 2011; Lund et al., 2012; Gahleitner, 2013]. Many challenges are faced for large scale PEMFC commercialisation, and water management is considered as a critical one, especially for the low/medium temperature PEMFCs. Water is unavoidable in PEMFCs due to the oxygen reduction reaction (ORR) at the cathode and the use of humidified reactant gases at both cathode and anode. An adequate amount of water is essential to a successful fuel cell operation, because a hydrated membrane and ionomer in the catalyst layers is required to maintain high conductivity. However, excess water may cause flooding inside the porous electrode and channel, resulting in a pronounced decrease in mass transport rate and thus reduction in the overall fuel cell performance.

Water transport through the membrane, in terms of three mechanisms: electro-osmotic drag (EOD), back diffusion and hydraulic permeation, determines the membrane/ionomer water content, which then significantly affects the membrane/ionomer conductivity. The liquid water formed in the porous electrode is mainly attributed to membrane/ionomer desorption (the membrane/ionomer water content reaches equilibrium) and water vapour condensation (partial pressure of water vapour exceeds the saturation pressure). At the anode side, hydrogen consumption could result in the humidified anode reactant gas becoming supersaturated with water vapour, which transfers to liquid water by condensation. Experimental studies have detected liquid water in the anode; more liquid water was observed at a high anode relative humidity [Wong et al., 2011; Iranzo et al., 2015]. However, anode flooding has not been considered in the majority of previous modelling research.

The amount of liquid water in the porous electrode is a consequence of the interaction between many parameters, such as contact angle, electrode porosity and microstructure, flow patterns, flow filed design, 
and operating conditions. Intensive experimental studies have been focused on novel gas diffusion layer (GDL) and catalyst layer (CL) materials [Park et al., 2012; Holdcroft, 2014], optimal PTFE content [Shimpalee et al., 2007; Park et al., 2008] and optimised operating conditions [Ge and Wang, 2007; Barelli et al., 2011]. For a CL with a fixed thickness, the increase in platinum loading and $\mathrm{Pt} / \mathrm{C}$ ratio could increase the CL porosity and the electrochemical active surface area (ECSA) [Xing et al.; 2013b]. The increased CL porosity facilitates gas transport and increases the CL ability to remove water due to the increased capillary diffusion coefficient [Wu et al., 2010; Yang et al., 2011]. In the meanwhile, the increased ECSA accelerates formation of liquid water due to the faster ORR process. The role of the GDL is to facilitate the transport of reactant and product gases, liquid water and heat between the channel and CL. Reactant gases can be uniformly dispersed when diffusing through GDL before reaching catalyst sites, which can then avoid local hot spots at electrodes near the inlet, created by the non-uniform distributed reactant concentration along its flow direction. A certain thickness of GDL is required for well dispersed reactant gases but it is at the expense of higher diffusion resistance, which could limit the fuel cell performance at high current densities. For liquid water transport through the GDL, the use of higher amount of hydrophobic materials could lead to the lower level of flooding [Pasaogullari and Wang, 2004a]. Application of micro-porous layers (MPL) has been an effective approach to mitigate liquid water flooding in the porous electrodes in many commercial cells. Cho and Mench (2012) directly visualised the liquid water profiles within a cell using hydrogen-deuterium contrast neutron radiography (NR), the MPL has proved to mitigate flooding in the cathode side through enhanced transport of water to the anode side. Despite many advanced understandings made by the studies, a complete investigation is still required to fully understand the role of all the factors that affect the anode performance and flooding. For example, up to now, the GDL thickness on temperature rise and strategies to mitigate flooding using novel flow field designs are still not well investigated in the literature. 
Mathematical models present a good platform for the complete investigation of all the interacting parameters in fuel cells. To accurately model the physical and chemical processes in GDLs, CLs and flow channels, the two-phase flow phenomenon between liquid water and gas mixture must be carefully considered. For this, the multi-phase mixture $\left(\mathrm{M}^{2}\right)$ model was firstly developed by Wang and Cheng (1996), in which the water-gas mixture was considered as a continuum flowing in porous media under capillary force. Later on, Wang and his co-workers [Wang et al., 2001; Basu et al., 2009] combined the volume of fluid (VOF) method with the $\mathrm{M}^{2}$ model to describe the liquid water transport in porous electrodes and flow channels. Pasaogullari and Wang (2004b) investigated the role of MPL in liquid water control using a twophase flow model. Weber and Newman (2005) quantified the effects of MPL using a two-phase flow and robust membrane model. By considering the partial occupation of the electrode void space by liquid water, the reduction in effective mass transport coefficient was highlighted by Nam and Kaviany (2003). The usefulness of the agglomerate model for treating the two-phase flow phenomenon in PEMFCs was first demonstrated by Shah et al. (2007), in which the additional oxygen transport resistance through a thin liquid water film surrounding the agglomerate was taken into account. The agglomerate model has later been applied to the phosphoric acid doped polybenzimidazole (PBI) membrane fuel cell by Sousa et al. (2010), in which the effect of phosphoric acid loading on the cell performance was successfully studied.

Building on these studies, we have developed an anode partial flooding model [Xing et al. 2016] for PEM fuel cells. The model is a two-dimensional, along-the-channel, two-phase flow and non-isothermal model, based on a spherical-agglomerate catalyst structure, combined with a comprehensive water phase-transfer and transport mechanism. The non-uniform distribution of membrane/ionomer water content due to the driving force of EOD, back diffusion and hydraulic permeation, the ionomer film swelling due to ionomer water uptake, as well as the water phase-change between vapour, dissolved water and liquid water are all 
considered. In our previous work [Xing et al. 2016], this anode partial flooding model was validated by comparing with experimental measurement. In this paper, we are using the anode partial flooding model to investigate the electrode properties, e.g. contact angle, porosity, platinum loading and GDL thickness, as well as channel geometries including length and depth, in relation to temperature distribution, water flooding and fuel cell performance. The model is also used to optimise electrode parameters and provide theoretical guidance to a novel channel design featured with multi- outlets and inlets, which is for the first time proposed.

\section{Model development}

\subsection{Model features and assumptions}

A 2D along-the-channel model for a typical fuel cell was developed. The model features and main assumptions are listed as follows:

(1) Fuel cell geometry and computational domain. The 2D representation of the geometry and computational domain is given in Fig. 1, showing flow channels (Domain 1), GDLs (Domain 2), and CLs (Domain 3) of both the anode and cathode, and a Nafion ${ }^{\circledR}$ membrane (Domain 4) in between. The initial input structural parameters and material properties of each layer are listed in Table 1.

(2) Structure of the catalyst layers. The catalyst layers are treated as spherical catalyst agglomerates with porous inter-agglomerate spaces defined as the primary pores. The void space between the agglomerates is defined as the secondary pores. As shown in Fig. 2, the primary pores inside the agglomerate are partially filled with the ionomer, whereas the catalyst agglomerates are in turn surrounded by ionomer and liquid water films, which partially occupy the secondary pores between the agglomerates.

(3) Reactant transport. The ideal gases assumption is applied on the feed gases at both anode and cathode, which transport through diffusion and advection in the porous electrodes. 
(4) Membrane. The membrane is assumed as non-permeable to hydrogen, oxygen and nitrogen. Only the transport of dissolved water and protons are accounted through the membrane.

(5) Liquid water. Liquid water in the CLs of both the anode and cathode is generated by water vapour condensation and membrane/ionomer desorption. For the hydrophobic cathode catalyst layer (CCL), as saturation increases, liquid water is firstly generated in the secondary pores and coat the catalyst agglomerates as a thin film after formation.

(6) Dissolved water. Water absorbed in the membrane/ionomer is in the dissolved phase, which enters the membrane/ionomer from the vapour phase during water uptake and leaves the membrane/ionomer in the liquid phase during membrane/ionomer desorption. The product water in the CCL is generated in the dissolved phase.

(7) Membrane and ionomer swelling. Membrane swelling is omitted. However, ionomer in the CLs swells as a function of its water content.

\subsection{Conservation equations}

\subsubsection{Mass balance and transport}

For compressible Newtonian fluids in steady-state conditions, the continuity equation and Navier-Stokes equation are used to describe the mass balance and variation of velocity and pressure of species flowing inside the flow channels and porous electrodes, including GDLs and CLs.

$$
\begin{aligned}
& \nabla \cdot\left(\rho^{g} \mathbf{u}^{g}\right)=S_{m} \\
& \rho^{g}\left(\mathbf{u}^{g} \cdot \nabla \mathbf{u}^{g}\right)=-\nabla p-\nabla \mu^{g}\left[\nabla \mathbf{u}^{g}+\left(\nabla \mathbf{u}^{g}\right)^{T}-\frac{2}{3}\left(\nabla \cdot \mathbf{u}^{g}\right) I\right]+F
\end{aligned}
$$

where $\mathbf{u}^{g} \cdot \nabla \mathbf{u}^{g}$ is convective acceleration, $\nabla p$ is pressure gradient, $F$ is the force from other source, $I$ is the identity matrix, $\mathbf{u}^{g} \quad\left(\mathrm{~m} \mathrm{~s}^{-1}\right), \rho^{g}\left(\mathrm{~kg} \mathrm{~m}^{-3}\right)$ and $\mu^{g} \quad(\mathrm{~Pa} \mathrm{~s})$ is the velocity, density and viscosity of the 
gas mixture, respectively. $S_{m}\left(\mathrm{~kg} \mathrm{~m}^{-3} \mathrm{~s}^{-1}\right)$ is the source term, consisting of the source terms of hydrogen, oxygen and water vapour as shown in Table 4.

For the conservation of species, Maxwell-Stefan equation is used to calculate the mole fractions of gas species in the gas mixture shown as follows:

$$
\rho^{g} \mathbf{u}^{g} \cdot \nabla w_{i}^{g}-\nabla \cdot\left[\rho^{g} \sum_{j=1}^{N}\left(1-s^{\prime}\right) D_{i j}\left(\nabla x_{j}^{g}-w_{j}^{g}\right) \frac{\nabla p}{p}+D_{i}^{T} \frac{\nabla T}{T}\right]=M_{i} S_{i}^{g}
$$

where $w_{i}^{g}$ and $x_{j}^{g}$ is the mass fraction and mole fraction of the species $i$, respectively, $p(\mathrm{~Pa})$ is the pressure, $T(\mathrm{~K})$ is the temperature, $D_{i j}\left(\mathrm{~m}^{2} \mathrm{~s}^{-1}\right)$ and $D_{i j}^{T}\left(\mathrm{~kg} \mathrm{~m}^{-1} \mathrm{~s}^{-1}\right)$ are the multi-component diffusion and thermal diffusion coefficient of gas species, which can be calculated by the following equations proposed by Bird et al. (2002):

$$
\begin{aligned}
& D_{i j}=1.8583 \times 10^{-7} T \sqrt{\left(\frac{1}{M_{i}}+\frac{1}{M_{j}}\right)} T / p \sigma_{i j}^{2} \Omega_{i j} \\
& D_{i}^{T}=M_{i} k_{i} / c_{p, i}
\end{aligned}
$$

where $M_{i}\left(\mathrm{~kg} \mathrm{~mol}^{-1}\right)$ is the molecular weight for specie $i, k_{i}\left(\mathrm{~W} \mathrm{~m}^{-1} \mathrm{~K}^{-1}\right)$ and $c_{p, i}\left(\mathrm{~J} \mathrm{~mol} \mathrm{~K}^{-1}\right)$ is the thermal conductivity and specific heat capacity of gas species, respectively.

In Eq. (3), s' is the corrected water saturation, which is defined as the volume fraction of the secondary pores occupied by the liquid water.

$$
s^{\prime}=s \varepsilon_{C L} / \varepsilon_{s}
$$

where $\varepsilon_{C L}$ and $\varepsilon_{s}$ is the CL porosity and volume fraction of the secondary pores, respectively. The CL properties are given in detail in Section 2.5.

\subsubsection{Non-isothermal heat transport}

By assuming all phases are in thermal equilibrium, the multiphase heat transfer process is described by the following equation. 


$$
\nabla \cdot\left[\sum_{i=g, l}\left(\varepsilon \rho c_{p} \mathbf{u}\right)_{i} T\right]-\nabla \cdot\left(\sum_{i=g, l, s} k_{i} \nabla T\right)=S_{T}
$$

Heat generation originating from reaction, Joule heating (ohmic heating) and water phase transfers are all considered in the source term. Note that the hydrogen oxidation reaction (HOR) in the anode is endothermic whereas the ORR in the cathode is exothermic. In the equation above, the subscript $i$ refers to gas mixture, liquid water and solid phase of the electrode. The effective thermal conductivity and specific heat capacity depend on the volume fractions of the species within a chosen domain. Without a doubt, the CCL is the most complicated domain in which gas mixture, liquid water, ionomer, Pt/C, penetrated GDL are all involved. The detailed expressions for the effective thermal conductivity, specific heat capacity of GDL, CL and membrane/ionomer are listed in Table 2.

The specific heat capacity and the thermal conductivity of the gas mixture are obtained by using an empirical equation developed by Wilke (1950),

$$
c_{p}^{g}=\sum_{i} x_{i} c_{p, i}^{g}, \quad k^{g}=\sum_{i} \frac{x_{i} k_{i}}{\sum_{j} x_{j} \Phi_{i j}}
$$

in which

$$
\Phi_{i j}=\frac{1}{\sqrt{8}}\left(1+\frac{M_{i}}{M_{j}}\right)^{-0.5}\left[1+\left(\frac{k_{i}}{k_{j}}\right)^{0.5}\left(\frac{M_{j}}{M_{i}}\right)^{0.25}\right]^{2}, \quad \Phi_{j i}=\frac{k_{j}}{k_{i}} \frac{M_{i}}{M_{j}} \Phi_{i j}
$$

\subsubsection{Conservation of charge}

In the CLs of both the anode and cathode, the conservation of charge results in the following equation:

$$
\nabla i_{s}+\nabla i_{M}=0
$$

According to Ohm's law, the governing equations for the electronic and ionic charge transport are:

$$
i_{s}=-\sigma_{s}^{e f f} \nabla \varphi_{s}, \quad i_{M}=-\sigma_{M}^{e f f} \nabla \varphi_{M}
$$

where $\phi_{s}$ and $\phi_{M}(\mathrm{~V})$ is the potential of solid phase and electrolyte phase, respectively. $\sigma_{s}^{\text {eff }}$ and $\sigma_{M}^{\text {eff }}$ (S $\mathrm{m}^{-1}$ ) is the effective electronic and ionic conductivity of the catalyst layer, respectively, which is obtained by 
using the Bruggeman correction and the equation developed by Kamarajugadda and Mazumder (2008) as:

$$
\begin{aligned}
& \sigma_{s}^{e f f}=\left(L_{P t / C}\right)^{1.5} \sigma_{s} \\
& \sigma_{M}^{e f f}=\left(1-\varepsilon_{C L}\right)\left[1+\frac{\left(\% M \varepsilon_{C L}-1\right)}{\left(1+\delta / r_{a g g}+a_{0}\right)^{3}}\right] \sigma_{M}
\end{aligned}
$$

The intrinsic membrane conductivity depends on the temperature and water content, which can be

expressed as [Ju et al., 2005; Webber and Newman, 2006]:

$$
\sigma_{M}=\exp \left[1268\left(\frac{1}{303}-\frac{1}{T}\right)\right](0.5139 \lambda-0.326)
$$

The overpotential for each electrode is defined as

$$
\eta_{i}=\phi_{s}-\phi_{M}-\phi_{i}^{e q}
$$

where $\phi_{i}^{e q}(\mathrm{~V})$ is zero for anode and equals to the equilibrium cell potential for cathode.

The cell voltage is calculated by the following equation:

$$
E^{\text {cell }}=E^{0}-\eta_{a}-\left|\eta_{c}\right|-i_{M} R_{M}
$$

where $E^{0}(\mathrm{~V})$ is the open circuit potential (OCP) which equals to $\phi_{c}^{e q}$ minus $\phi_{a}^{e q}$ [Ismail, 2012].

$$
E^{0}=\phi_{c}^{e q}-\phi_{a}^{e q}=1.482-8.45 \times 10^{-4} T+4.31 \times 10^{-5} \ln \left(p_{H_{2}} p_{O_{2}}^{0.5}\right)
$$

Eqns. (1-6) are applied on domain 1, 2 and 3 except the membrane, while Eqns. (7-17) are applied on all domains.

\subsection{Liquid water transport}

By applying the volume average approach to the continuity equation and using Darcy's law for both the liquid and gas phases, the governing equation of the liquid water transport was expressed as follow:

$$
\nabla \cdot\left(\rho_{w}^{l} D_{c} \nabla s-\frac{\rho_{w}^{l} k_{r}^{l} \mu_{w}^{g}}{k_{r}^{g} \mu_{w}^{l}} \mathbf{u}^{g}\right)=M_{w} S_{w}^{l}
$$

where $\rho_{w}^{l}\left(\mathrm{~kg} \mathrm{~m}^{-3}\right)$ is the liquid water density, $M_{w}\left(\mathrm{~kg} \mathrm{~m}^{-1}\right)$ is the water molecular weight, $\mu_{w}^{g}$ and $\mu_{w}^{l}$ (Pa s) is the dynamic viscosity of water vapour and liquid water, respectively. $k_{r}^{g}$ and $k_{r}^{l}$ is the relative 
permeability of gas and liquid phase, respectively.

The capillary diffusion coefficient, $D_{c}\left(\mathrm{~m}^{2} \mathrm{~s}^{-1}\right)$, is calculated using the following expression [Pasaogullari and Wang, 2004a; 2004b]:

$$
D_{c}=-\frac{k_{r}^{l}}{\mu_{w}^{l}} \sigma \cos \left(\theta_{c}\right)\left(\varepsilon k_{p}\right)^{1 / 2} \frac{d J(s)}{d s}
$$

where $\theta_{c}\left({ }^{\circ}\right)$ is the contact angel, $k_{p}\left(\mathrm{~m}^{2}\right)$ is the hydraulic permeability of the porous media, $J(s)$ is the Leverett function, which is defined as:

$$
J(s)= \begin{cases}1.417(1-s)-2.120(1-s)^{2}+1.263(1-s)^{3} & \theta_{c}<90^{\circ} \\ 1.417 s+2.120 s^{2}-1.263 s^{3} & \theta_{c}>90^{\circ}\end{cases}
$$

The water vapour saturation pressure, $p_{s a t}(\mathrm{~Pa})$, is a function of temperature, given as:

$$
p_{s a t}=9.531 \times 10^{-4}(T-237)^{4}-3.123 \times 10^{-2}(T-237)^{3}+3.451(T-237)^{2}+20.96(T-237)+611.0
$$

Eqns. (18-21) are solved for domain 1, 2 and 3 except the membrane.

\subsection{Dissolved water transport}

Three forces are taken into account for the dissolved water transport through the membrane. By following a diffusive approach, the conservation equation is described as follows:

$$
\nabla \cdot\left(n_{d} \frac{i_{M}}{F}\right)-\nabla \cdot\left(D_{w-M} \nabla c_{w}^{d}\right)-\nabla \cdot\left(\frac{k_{p, M} c_{w}^{d}}{\mu_{w}} \nabla p\right)=S_{w}^{d}
$$

The term on the left of the equation refer respectively to water migration by EOD, back diffusion and hydraulic permeation, where $c_{w}^{d}\left(\mathrm{~mol} \mathrm{~m}^{-3}\right)$ is the concentration of dissolved water, $n_{d}$ is the EOD coefficient, $D_{w-M}\left(\mathrm{~m}^{2} \mathrm{~s}^{-1}\right)$ is the diffusion coefficient of water through the membrane/ionomer, $k_{p, M}$ $\left(\mathrm{m}^{2}\right)$ is the hydraulic permeability of water in membrane and $\mu_{w}(\mathrm{~Pa} \mathrm{~s})$ is the water viscosity.

When Nafion ${ }^{\circledR}$ membrane/ionomer water uptake occurred, membrane/ionomer swells and leads to volume expansion, which reduces the CL porosity and enlarges the ionomer film thickness surrounding the agglomerate, resulting in a decline of cell performance in most of cases [Xing et al. 2014a, 2014b, 2015]. 
The concentration of dissolved water depends on the membrane/ionomer water content according to the following relation [Shah et al., 2007]:

$c_{w}^{d}=\frac{\rho_{M}}{E W} \frac{\lambda}{1+k_{s} \lambda}$

where $E W\left(\mathrm{~g} \mathrm{~mol}^{-1}\right)$ is the equivalent weight of membrane/ionomer, $\rho_{M}\left(\mathrm{~kg} \mathrm{~m}^{-3}\right)$ is the density of dry membrane/ionomer, $k_{s}$ is the ionomer swelling coefficient.

$c_{w}^{e q}\left(\mathrm{~mol} \mathrm{~m}^{-3}\right)$ is the equilibrium dissolved water concentration, which was determined by the equilibrium water content according to Eq. (23). The equilibrium water content is determined by empirical correlations which were based on water uptake measurements [Wu et al., 2010], given as

$$
\lambda^{e q}=16.8 s+14.0(1-s) \quad s>0
$$

The actual water content was proposed as a function of water activity:

$$
\lambda=0.043+17.81 \alpha_{w}-39.85 \alpha_{w}^{2}+36.0 \alpha_{w}^{3} \quad \alpha_{w} \leq 1
$$

where $\alpha_{w}$ is a function of both water vapour partial pressure and liquid water saturation [Yang et al., 2011], expressed as:

$$
\alpha_{w}=x_{w} \frac{p}{p_{s a t}}+2 s
$$

Note that the diffusion coefficient of water through the membrane/ionomer is a piecewise function which is determined by temperature and water content via:

$$
\begin{aligned}
& D_{w-M}=\left\{\begin{array}{lr}
D_{w-M}^{0}\left(2.563-0.33 \lambda+2.64 \times 10^{-2} \lambda^{2}-6.71 \times 10^{-4} \lambda^{3}\right) & \lambda>4 \\
D_{w-M}^{0}(6.65-1.25 \lambda) & 3<\lambda \leq 4 \\
D_{w-M}^{0}\left(2.05 D_{w-M}^{0}-3.25\right) & 2<\lambda \leq 3
\end{array}\right. \\
& D_{w-M}^{0}=1.0 \times 10^{-10} \exp [2416(1 / 303-1 / T)]
\end{aligned}
$$

Eqns. (22-27) are solved on domain 3 and 4, CLs of both the anode and cathode and the membrane. The conservation of water in different phases and heat within different computational domain is shown in detail 
in Table 3. The source terms in the governing equation (1), (3), (7), (18) and (22) were given in Table 4.

\subsection{Catalyst layer property}

Based on the two-phase flow agglomerate model developed previously [Xing et al., 2013a; 2013b; 2014],

the key structural parameters of the catalyst layers are shown as follows:

Volume fraction of Pt/C: $L_{P t / C}=\frac{m_{P t}}{l_{C L}}\left(\frac{1}{\rho_{P t}}+\frac{1-f}{f} \frac{1}{\rho_{C}}\right)$

Catalyst layer porosity: $\varepsilon_{C L}=1-L_{M}-L_{G D L}\left(1-\varepsilon_{G D L}\right)-\frac{m_{P t}}{l_{C L}}\left(\frac{1}{\rho_{P t}}+\frac{1-f}{f} \frac{1}{\rho_{C}}\right)$

Catalyst agglomerate density: $\quad N_{a g g}=\frac{3 L_{P t / C}}{4\left(1-\varepsilon_{C L}\right) \pi r_{a g g}{ }^{3}}$

Ionomer film thickness: $\delta_{M}=r_{a g g}\left(\sqrt[3]{\frac{\left(1-\varepsilon_{C L}\right)\left(1-\varepsilon_{C L}-L_{S}\right)+L_{P t / C} \varepsilon_{C L}(1-\% M)}{L_{P t / C}}}-1\right)$

Liquid water film thickness: $\delta_{w}=\sqrt[3]{\left(r_{a g g}+\delta_{M}\right)^{3}+\frac{3 s \varepsilon_{C L}}{4 \pi N_{a g g}}}-\left(r_{a g g}+\delta_{M}\right)$

Agglomerate specific area: $a_{a g g}=\frac{m_{P t} A_{s}}{l_{C L}} \frac{\left(1-\varepsilon_{C L}\right)}{L_{P t / C}}$

Eqns. (28-33) are applied on domain 3, CLs of both the anode and cathode. Details can be found elsewhere

[Xing et al. 2013a, 2013b, 2014a, 2014b, 2015].

\subsection{Reactant gas diffusion and reaction}

By taking the Knudsen diffusion into account, the equivalent coefficient for oxygen diffusing within the cathode void space is given as follows:

$$
\frac{1}{D_{i-P}}=\frac{1}{D_{i-g}}+\frac{1}{D_{K n, i}}
$$

where $D_{i-P}\left(\mathrm{~m}^{2} \mathrm{~s}^{-1}\right)$ is the equivalent diffusion coefficient of gas species through the porous media, $D_{i-g}$ $\left(\mathrm{m}^{2} \mathrm{~s}^{-1}\right)$ is the intrinsic diffusion coefficient of gas species in the gas mixture, and $D_{K n, i}\left(\mathrm{~m}^{2} \mathrm{~s}^{-1}\right)$ is the Knudsen diffusion coefficient of species $i$. Knudsen diffusion is taken into account due to its significant 
impact on gas transport through porous media with pore diameters in nanometer level. The Knudsen diffusion coefficient is given as:

$$
D_{K n, i}=\frac{d_{a v g}}{3} \sqrt{\frac{8 R_{g} T}{\pi M_{i}}}
$$

where $d_{\text {avg }}(\mathrm{m})$ is the average pore diameter of the agglomerate, obtained as:

$$
d_{\text {avg }}=\frac{4 \varepsilon_{a g g, p}}{3\left(1-\varepsilon_{a g g, p}\right)} r_{a g g}
$$

The intrinsic diffusion coefficient of gas species in the gas mixture is expressed as:

$$
D_{i-P}=\frac{1-x_{i}}{\sum_{i \neq j}\left(x_{j} / D_{i-j}\right)}
$$

Due to the fact that the liquid water is generated in cathode, the secondary pores of the CCL are partially filled by the liquid water which leads to a loss of the void space for gas diffusion. Therefore, the effective diffusion coefficient for oxygen diffusing through the CCL is corrected by the water saturation as follows:

$$
D_{i, s}^{e f f}=\left[\varepsilon_{s}\left(1-s^{\prime}\right)\right]^{1.5} D_{i-P}
$$

According to the assumption, the primary pores are partially filled with ionomer. Gas species diffusion within the agglomerate is consequently calculated by:

$$
D_{i, p}^{e f f}=\left(\% M \varepsilon_{C L}\right)^{1.5} D_{i-M}+\left[(1-\% M) \varepsilon_{C L}\right]^{1.5} D_{i-P}
$$

For the oxygen diffusivity and Henry's constant through the Nafion ${ }^{\circledR}$ ionomer, improved equations are developed as follows by taking the effects of both the temperature and water content into account [Xing et al., 2014].

$$
\begin{aligned}
& D_{O_{2}-M}=1.3926 \times 10^{-10} \lambda^{0.708} \exp \left(\frac{T-273.15}{106.65}\right)-1.6461 \times 10^{-10} \lambda^{0.708}+5.2 \times 10^{-10} \\
& H_{O_{2}}=0.11552 \exp \left(14.1+0.0302 \lambda-\frac{666}{T}\right)
\end{aligned}
$$

The Henry's constant of hydrogen dissolution in Nafion ${ }^{\circledR}$ ionomer is defined as constant $4.56 \times 10^{3}\left(\mathrm{~Pa} \mathrm{~m}{ }^{3}\right.$ 
$\mathrm{mol}^{-1}$ ) [Bernardi and Verbrugge, 1992; Marr and Li, 1999]. Due to the lack of studies regarding hydrogen diffusion through the Nafion ${ }^{\circledR}$ ionomer, the hydrogen diffusivity is assumed to be two times of that of oxygen [Cheddie and Munroe, 2013; Chippar and Ju, 2013].

The electrochemical reactions occur when the reactant gas reaches the catalyst active site. The volumetric current density based on the agglomerate model is obtained using the following equation: [Sun et al., 2005;

Shah et al., 2007; Kamarajugadda and Mazumder, 2008; Khajeh-Hosseini-Dalasm et al., 2012]

$$
i_{\text {agg,i }}=n_{i} F\left(\frac{p_{i}}{c_{i}^{r e f} H_{i}}\right)^{\gamma}\left[\frac{1}{E_{a g, i} k_{a g g, i}}+\frac{r_{a g g}+\delta_{M}+\delta_{w, i}}{r_{a g g}}\left(\frac{\delta_{M}}{a_{a g g, i}^{M} D_{i-M}}+\frac{\delta_{w, i}}{a_{a g g, i}^{w} D_{i-w}}\right)\right]
$$

where

$$
k_{a g g, i}=\frac{a_{a g g, i}^{M} i_{0, i}^{r e f}}{n_{i} F}\left[\exp \left(\frac{-\alpha_{R d, i} F \eta_{i}}{R T}\right)-\exp \left(\frac{\alpha_{O x, i} F \eta_{i}}{R T}\right)\right]
$$

where the subscript $i$ is for anode and cathode, respectively, and the superscript $\gamma$ equals to 0.5 for hydrogen oxidation reaction (HOR) in anode and 1.0 for ORR in cathode. $p_{i}(\mathrm{~Pa})$ and $k_{a g g, i}\left(\mathrm{~s}^{-1}\right)$, is the partial pressure and reaction rate coefficient of species $i$, respectively. $E_{a g g, i}$ and $\delta_{w, i}$ (m) is the effectiveness factor and liquid water film thickness at the anode and cathode, respectively.

The effectiveness factor of the agglomerate is given by

$$
E_{a g g, i}=\frac{1}{M_{T, i}}\left[\frac{1}{\tanh \left(3 M_{T, i}\right)}-\frac{1}{3 M_{T, i}}\right]
$$

where $M_{T, i}$ is the Thiele's modulus for spherical agglomerate, giving as

$$
M_{T, i}=\frac{r_{a g g}}{3} \sqrt{\frac{k_{a g g, i}}{D_{i, a g g}^{e f f}}}
$$

The electrochemical, physical and other temperature and water content dependent parameters are listed in Table 5 and Table 6, respectively.

Eqns. (34-39) are solved on domain 2 and 3, GDLs and CLs of both the anode and cathode. Eqns. (40-45) 
are applied on domain 3, the anode and cathode CLs only.

\subsection{Boundary conditions}

At the anode inlet (A'-B') and cathode inlet (G-H) as shown in Fig. 1, the temperature, mole fractions of reactant gases in gas mixture, and liquid water saturation are given as below:

$$
\begin{aligned}
& T=T_{a}^{0}, x_{w, a}^{0}=\frac{p_{s a t} R H_{a}}{p_{a}}, \quad x_{H_{2}}^{0}=1-x_{w, a}^{0}, \quad s_{a}=0 \\
& T=T_{c}^{0}, \quad x_{w, c}^{0}=\frac{p_{s a t} R H_{c}}{p_{c}}, \quad x_{O_{2}}^{0}=0.21\left(1-x_{w, c}^{0}\right), \quad x_{N_{2}}^{0}=0.79\left(1-x_{w, c}^{0}\right), \quad s_{c}=0
\end{aligned}
$$

The gas velocities at the inlets of both electrodes are related to their stoichiometric flow ratio shown as follows:

$$
\mathbf{u}_{a}^{g, 0}=\frac{\xi_{a} R T i^{r e f} A_{M}}{2 F p_{a} x_{H_{2}} A_{c h}}, \quad \mathbf{u}_{c}^{g, 0}=\frac{\xi_{c} R T i^{r e f} A_{M}}{4 F p_{c} x_{O_{2}} A_{c h}}
$$

where $i^{r e f}$ is the reference current density (defined as $1.0 \mathrm{~A} \mathrm{~cm}^{-2}$ in this study), $\xi_{a}$ and $\xi_{c}$ is the stoichiometric flow ratio of the anode and cathode, respectively. $A_{M}\left(\mathrm{~m}^{2}\right)$ and $A_{c h}\left(\mathrm{~m}^{2}\right)$ is the effective area of electrode and the cross-sectional area of channel, respectively.

At the outlets of the anode (A-B) and cathode ( $\left.\mathrm{G}^{\prime}-\mathrm{H}^{\prime}\right)$, the pressure was given as a boundary condition.

$$
p_{a}=p_{a}^{0}, \quad p_{c}=p_{c}^{0}
$$

The water content on the GDL-CL interfaces of anode (C-C') and cathode (F-F') are defined as Dirichlet boundaries with the values according to Eq. (25) and (26).

\subsection{Numerical solution}

The numerical solution of the fully coupled governing equations is based on the finite element method 
(FEM). First of all, a mesh is developed over the computational domain by dividing it into numerous elements. The distance between each element is known as the step. At each step, the equations accounting for different phenomena are fully coupled and computed with the boundary conditions. Initial value is given to each parameter at the first attempt then followed by an iterative process until the calculation error is smaller than $10^{-5}$ (A convergence analysis was carried out and showed that a residual value of $10^{-5}$ is good enough to give reliable results). Commercial software COMSOL Multiphysics 4.4 is used to implement the fully coupled equations on a personal computer with Inter Core i7 $2.00 \mathrm{GHz}$ CPU and 8.00 GB RAM. The key to successfully solving this model is simulating the membrane/ionomer water content, which significantly affects many critical parameters, i.e. ionomer volume fraction, EOD coefficient, ionic conductivity, hydraulic permeability and water diffusivity.

\section{Model verification and validation}

\subsection{Mesh independence}

The geometry properties and mesh characters of the studied PEM fuel cell are shown in Fig. 3. The computation error in the solution related to the mesh grid disappears for an increasingly fine mesh. Considering that the impact of mesh characters on the modelling results is increased at high current density, a suitable mesh grid for the model is found by comparing the limiting current densities (predicted at the cell voltage of $0.05 \mathrm{~V}$ ) at various mesh grids. Nine groups of mesh grids as shown in Table 7 are evaluated. Note that the number of elements was fixed at 300 along the channel length and vary along the depth/thickness of different domains, including channels, GDLs, CLs and membrane. Three levels of element number on each domain are investigated and the increase in total number of elements of $1.2 \times 10^{4}$ is guaranteed of each modelling process. The current density at $0.05 \mathrm{~V}$ as shown in Table 7 reaches an asymptotic value as the consequence of the increased number of the mesh elements. Using any mesh finer than Grid 6 results in a 
constant current density but increases computational duration. To balance both the computational accuracy and the duration, Grid 6 is selected considering a sufficient reliability to ensure mesh independence with acceptable computing time.

\subsection{Model validation}

The modelling results are validated by the experimental data for two cases, in-house and selected from the work of Wang et al. (2003), as shown in Fig. 4. Details of MEA preparation and fuel cell testing can be found elsewhere [Kumar and Scott, 2012; Xing et al., 2014]. Parameters used for model validation are listed in Table 8. For the in-house case, parameters are measured experimentally while for the case of Wang et al. (2003) parameters are selected from their paper. Note that the cathode transfer coefficient $\left(\alpha_{c}\right)$ is obtained by fitting the experimental polarisation curves in the kinetics control zone (cell voltage higher than $0.8 \mathrm{~V}$ ) (Barbir, 2005).

Figure 4 shows a good consistency between the modelling results and the experimental data. The agreement is very good, especially at high cell voltages $(>0.5 \mathrm{~V})$, due to the relatively slow electrochemical reaction and weak impact of mass transport in this region. Due to various losses such as activation loss, Ohmic loss and concentration polarisation loss, the cell voltage typically falls with the increase in current density, which is also captured by the model. The model-predicted cell voltage is almost identical with experimental results in a wide range of current densities up to $1.0 \mathrm{~A} \mathrm{~cm}^{-2}$ for the in-house case and $0.9 \mathrm{~A} \mathrm{~cm}^{-}$

${ }^{2}$ for the data taken from Wang et al. (2003). The results in Fig. 4 clearly demonstrate that our model is able to predict the cell voltage very well in the normal range of operating current densities $\left(0-1.0 \mathrm{~A} \mathrm{~cm}^{-2}\right)$ and also the trend at higher current densities where a more rapid drop in cell voltage is observed with experimental results at higher current densities. The discrepancy between the modelling and experimental cell voltage at very high current densities is small, especially for the in-house case $\left(\sim 10 \%\right.$ at $\left.1.4 \mathrm{~A} \mathrm{~cm}^{-2}\right)$. 
This small discrepancy is caused by the increased mass transport resistance. At high current densities, more water is formed due to the accelerated electrochemical reaction. The formation of liquid water within the void space of the electrode may limit the oxygen diffusion, especially near the channel outlets where liquid water is prone to accumulation. As a result, it is expected that the oxygen transport resistance through the porous electrode, which is determined by both the electrode structure and reactant gas provided (e.g. the porosity of the electrode and the mole fraction of oxygen against nitrogen and vapour in the cathode channel), is increased. The 2D model used in this paper does not take into account the heterogeneity of the electrode structure in the third dimension. This leads to an under-estimation of the oxygen transport resistance and therefore an over-estimation of the current densities in comparison with the experimental data. The discrepancy is more apparent for large size cells at high current densities as large size cells have more heterogeneity in the electrode structure. This is a disadvantage of the 2D models, which indicates that future development should pay attention to 3D models.

\section{Results and discussions}

\subsection{The effect of contact angle in GDL on liquid water saturation}

Liquid water saturation is an indicator of the degree of flooding inside the porous electrodes and channels, which is defined as the volume fraction of void space occupied by liquid water. Liquid water saturation is a dimensionless parameter, which equals to unity when the void space of the porous media is fully filled with water. The effect of contact angle on liquid water saturation in the GDLs of the anode and cathode is shown in Fig. 5. Liquid water on hydrophobic electrode surface exhibits a contact angel larger than $90^{\circ}$. Thus, according to Eq. (19), capillary diffusion coefficient of liquid water through the porous electrode is proportional to the contact angel. It can be seen from Fig. 5a that the liquid water saturations in both the GDLs of the anode and cathode increase as the contact angle decreases. This can be explained by the 
improved hydrophobic property of the GDL. Due to the fact that the diffusion media are composite structures with hydrophobic and hydrophilic component, the composite contact angle is determined by the volume fractions of the hydrophobic and hydrophilic component. The increase in contact angle means more hydrophobic component is used. This is capable of increasing the capillary diffusion coefficient of the water through the diffusion media. It is shown in both Fig.5b and Fig.5c that, more apparent non-uniform distribution of liquid water is observed along the gas flow than that through the electrode thickness, especially near the outlets of both the anode and cathode. Comparing the gradients of liquid water saturations in Fig.5b and Fig.5c indicates that liquid water formation in the cathode GDL is more significant. Moreover, the distribution of liquid water in the cathode GDL is more non-uniform, both in-plane and through-plane, in comparison with that in the anode GDL. The porous electrodes are likely filled with liquid water in the over-humidified environment. It is expected that more hydrophobic electrodes would suffer from water starvation and thus a higher mass transport limiting current density occurs.

\subsection{The effect of GDL porosity on liquid water saturation}

The liquid water saturation in the GDLs of the anode and cathode with various GDL porosities are shown in Fig. 6. It is shown in both Fig. 6a and Fig. 6b that the increase in GDL porosity increases the liquid water saturation inside the GDLs of the anode and cathode. This can be attributed to the increased void space for water vapour condensation when the GDL porosity is increased. At $0.3 \mathrm{~V}$, the increase in GDL porosity from $20 \%$ to $80 \%$ increases the liquid water sources term $\left(S_{w}^{l}\right)$ (which is a direct indicator of the level of water vapour condensation) from 3.72 to $16.41\left(\mathrm{~mol} \mathrm{~m}^{-3} \mathrm{~s}^{-1}\right)$ in the anode GDL and from 27.55 to $46.81\left(\mathrm{~mol} \mathrm{~m}^{-3}\right.$ $\mathrm{s}^{-1}$ ) in the cathode GDL, respectively, according to the source terms in Table 3 and Table 4. For the anode GDL at $0.3 \mathrm{~V}$, the average liquid water saturation is $12 \%$ and $17 \%$ (calculated using Eq. 18) at the porosity of $20 \%$ and $80 \%$, respectively. Due to the fact that the liquid water saturation is defined as the volume 
fraction of void space occupied by liquid water, the volume fraction of the remaining void space without liquid water occupation is $17.6 \%$ and $66.4 \%$ at the porosity of $20 \%$ and $80 \%$, respectively. For the cathode GDL, there are still an average of $16 \%$ and $60 \%$ of the void space unoccupied by liquid water with GDL porosities of $20 \%$ and $80 \%$ respectively. As shown in Table 10 , the current density predicted at $0.3 \mathrm{~V}$ is increased from 0.821 to $1.593 \mathrm{~A} \mathrm{~cm}^{-2}$ as the GDL porosity is increased from $20 \%$ to $80 \%$.

It is also clear that the effect of GDL porosity on liquid water saturation is more significant when it increases from $20 \%$ to $40 \%$. The further increase of the porosity from $60 \%$ to $80 \%$ results in a small contribution to the liquid water saturation, in particular at the anode. Fig. 6a clearly indicates that, with the GDL porosities increased from $60 \%$ to $80 \%$, the liquid water saturation levels in the anode GDL remain almost constant. This can be explained by the fact that the increase in porosity also increases the possibility of liquid water evaporation. The equilibrium between water vapour condensation and liquid water evaporation is achieved at a particular GDL porosity. High GDL porosity is of benefit to the cell performance but it will be a challenge to the mechanical issues of the GDL. The clamping force between the bipolar plates may lead to structure failure of the GDL [Mason et al., 2013], and carbon corrosion may result in a more significant impact on the performance degradation. Based on the above results, we can conclude that the optimal GDL porosity is $40 \%$.

\subsection{The effect of platinum loading on liquid water saturation and CCL effectiveness factor}

Fig. 7 shows the liquid water saturation in the CCL with various platinum loadings. It is seen that the increase in platinum loading increases the liquid water saturation in the CCL. However, the increase in the liquid water saturation is not proportional to the increase in platinum loading. This can be explained by the fact that, at fixed $\mathrm{Pt} / \mathrm{C}$ ratio and catalyst layer thickness, the increase in platinum loading simultaneously increases the specific area and decreases the catalyst layer porosity [Xing et al., 2013b]. The decrease in 
porosity offsets the improved cell performance resulting from the increased reaction rate. In this condition, the reactant gas transport becomes the dominant process, resulting in an insufficient utilization of the platinum catalyst near the membrane.

The effectiveness factor, which accounts for the interaction between diffusion and reactions in porous media and indicates how sufficient the catalyst in the CCL is utilised, is shown in Fig. 8 with various platinum loadings. As the platinum loading increases, the CCL effectiveness factor decreases along two directions: reactant flowing along the channel and diffusion through the catalyst layer. The maximum effectiveness factor is observed at the CCL-GDL boundary near the cathode inlet, where the reactant gas firstly contacts the catalyst layer.

\subsection{The effect of the GDL thickness on temperature profiles and CCL effectiveness factor}

The temperature profiles along the cathode CCL-GDL interface with various GDL thicknesses at the cell voltage of $0.4-0.1 \mathrm{~V}$ are shown in Fig. 9. It is shown that the temperature rises (from the initial temperature of $343 \mathrm{~K}$ ) sharply near the cathode inlet and increases slowly along the direction of air flowing to the outlet. The sharp rise in temperature can be explained by the exothermic ORR inside the CCL and the relative high temperature near the outlet due to the heat released by water phase-transfer. According to our previous study [Xing et al. 2014a], more liquid water is generated and accumulated in the downstream channel; its phasetransfer contributes roughly $10 \%$ of total heat at the cathode at $1.0 \mathrm{~A} \mathrm{~cm}^{-2}$. Theoretically, greater fuel cell performance can be achieved with thinner GDL due to the reduced reactant diffusion resistance. However, this is at a cost of more significant temperature rise. In Fig. 9, six GDL thicknesses, 10, 20, 60, 100, 200 and $260 \mu \mathrm{m}$ are compared, in reference to the case of no GDL. It is found that the local temperature along the cathode CL-GDL interface is higher for thinner GDLs and the temperature distribution is more non-uniform for thinner GDL at low cell voltages (corresponding to high current densities). The reason for the higher 
temperature rise when use thinner GDL is due to the reduced heat transfer resistance and non-uniform distribution of reactant gases. The use of a GDL of $260 \mu \mathrm{m}$ decreases the local temperatures near the cathode outlet by $1.3{ }^{\circ} \mathrm{C}$ at $0.4 \mathrm{~V}$ and $5.8{ }^{\circ} \mathrm{C}$ at $0.1 \mathrm{~V}$, as shown in Fig. 9a and Fig. 9b respectively, compared to the case of no GDL. It is important to note that a further increase in GDL thickness larger than $200 \mu \mathrm{m}$ leads to only a slight change in temperature; for example, the increase in GDL thickness from 200 to $260 \mu \mathrm{m}$ has very little effect on the temperature rise.

The increase in GDL thickness also decreases the effectiveness factor of the cathode catalyst layer. The effectiveness factors of the CCL with various GDL thicknesses are shown in Fig. 10. The CCL effectiveness factor decreases along two directions, along the reactant gas flowing direction and through the CCL, and the gradient of CCL effectiveness factor is more significant through the CCL than that along the channel. The decrease in CCL effectiveness factor with a thicker GDL can be explained by the increase in reactant gas diffusion resistance, which may become the rate control process at high current density. In other words, the reactant consumption rate may be faster than the reactant diffusion rate through the GDL at high current density. In this condition, the relatively slow gas transport process controls the overall rate of the diffusionreaction process instead of the electrochemical reaction. For example, the increase in GDL thickness from 60 to $380 \mu \mathrm{m}$ leads to an average $28 \%$ decrease in the CCL effectiveness factor, which then reduces the current density from 1.68 to $1.37 \mathrm{~A} \mathrm{~cm}^{-2}$, approximately $19.0 \%$ decrease, at $0.3 \mathrm{~V}$.

\subsection{The effect of flow channel length and depth on liquid water saturation}

Fig. 11 shows the liquid water saturation, in both the anode and the cathode channels, with various channel lengths in the range of $0.5-4.0 \mathrm{~cm}$. At the cell voltage of $0.3 \mathrm{~V}$, the water generation rate is significantly fast, leading to a rapid accumulation of liquid water in the channel. It is shown in Fig. 11 that the liquid water distribution along the channel is non-uniform. The downstream regions are more easily affected by more 
severe water flooding. The longer the channel is, the more severe water flooding is observed in the downstream regions. At the anode outlets $(\mathrm{Y}=1)$ in Fig. 11a, the increase of channel length from 1.0 to 4.0 $\mathrm{cm}$ increased the liquid water saturation from $11 \%$ to $19 \%$. Similarly, the liquid water saturation is increased from $22 \%$ to $41 \%$ at the cathode outlet, as shown in Fig. 11b. It is important to note that the distribution of liquid water saturation over the channel depth (coordinate $\mathrm{X}$ ) is almost uniform. In addition, liquid water is not observed in particular regions near the inlet. This is in good agreement with Yang et al. (2011)'s work, who showed that the first $2 \mathrm{~cm}$ of a $20 \mathrm{~cm}$ cathode channel did not suffer from liquid water flooding. As indicated in Fig. 12, it is found that the length of such particular region is almost independent on the channel length applied. The length of the no liquid water saturation region, e.g. liquid water saturation less than $10 \%$, is identical for various channel lengths.

The liquid water saturations, in both the anode and the cathode channels, with various channel depths in the range of $0.5-2.0 \mathrm{~mm}$ at the cell voltage of $0.3 \mathrm{~V}$, are shown in Fig. 13. At a fixed stoichiometric flow ratio and a channel width, the velocity of the reactant gas varies inversely with the channel depth. The reactant gas flow is faster in a shallow channel, which could homogenise the spatial distribution of reactant gases along the channel and improve the water removal ability. In Fig. 13a, as the anode channel depth increases from 0.5 to $2.0 \mathrm{~mm}$, the maximum water saturation is decreased from $13 \%$ to $10 \%$. On the contrary, the maximum water saturation in the cathode channel is decreased from 0.25 to 0.19 as the cathode depth increases from 0.5 to $2.0 \mathrm{~mm}$. The effect of the cathode channel depth on water saturation is larger than that of the anode channel depth. As indicated in Table 10, an increase in channel depth from 0.5 to $2.0 \mathrm{~mm}$ leads to a decrease in current density from 1.37 to $1.32 \mathrm{~A} \mathrm{~cm}^{-2}$ at $0.3 \mathrm{~V}$. Moreover, the differential pressure between adjoining channels is increased for the shallow channel, thus the oxygen transfer rate to an electrode is increased by the gas flow through the GDL [Zhou et al., 2009]. 


\subsection{Parametric study}

A parametric study is carried out to study the effect of six parameters on the current densities at four levels.

The parameters are listed in Table 9. The predicted current densities corresponding to the four levels at three cell voltages are presented in Table 10. These studied parameters are related to the properties of the electrodes and channels, including platinum loading $\left(m_{\mathrm{Pt}}\right)$, GDL porosity $\left(\varepsilon_{\mathrm{GDL}}\right)$, GDL thickness $\left(\delta_{\mathrm{GDL}}\right)$, contact angel $(\theta)$, channel length $(L)$ and channel depth $\left(\delta_{\mathrm{Ch}}\right)$. The results indicate that the increase in GDL thickness and channel depth lead to a monotonically decrease in cell performance in the range of cell voltages from 0.7 to

$0.3 \mathrm{~V}$. This can be explained by the increased mass transport resistance and decreased velocity of reactant gases at a fixed stoichiometry. On the contrary, the current densities predicted at various cell voltages are almost proportional to the GDL porosity. Ideally, the mass transport of reactant gases can be reinforced when a high porosity is used. However, it is a challenge to the GDL mechanical strength and stability. Contact angle and channel length almost have no effect on the cell performance at high cell voltages (low current densities) due to the insignificant amounts of liquid water formed. As the cell voltages decreases, the corresponding current densities gradually increase, resulting in a significant formation of liquid water inside the electrodes and channels. In this condition, the effect of contact angle and channel length become more important due to the increased impact on the capillary coefficient of liquid water transport and the degree of liquid water flooding in the channel. The effect of platinum loading on current density is complicated. At high cell voltage, the current density is mainly determined by kinetics of electrochemical reactions rather than mass transport. Thus, the increase in platinum loading increases the current density due to the increased specific area of the catalyst layer [Xing et al., 2013b]. At low cell voltages, electrode porosity plays a vital important role in determining the current density as the rate control process turns to mass transport, especially the oxygen transport through the electrode. As a consequence, the increase in platinum loading decreases the 
current density at low cell voltages. At medium cell voltages, the cell performance is under a mixed control where both reaction kinetics and reactant transport approximately equally contribute to the current density. As a result, the current density is initially increased as the platinum loading increases, and then decreased with a further increase in platinum loading beyond the optimal value.

\subsection{The novel flow channel design}

Due to the accumulation of liquid water downstream the channel, a long channel is prone to suffering from reactant gas mass transport problems. On the contrary, short channel may have the problem of insufficient electrochemical reactions. In other words, the reactant gases in short channels are not completely electrochemically reacted. As indicated in Table 10, when other parameters are fixed constantly in base-case condition shown in Table $8,1 \mathrm{~cm}$ is the optimal channel length among the four channel lengths of $0.5,1.0$, 2.0 and $4.0 \mathrm{~cm}$. In order to mitigate the impact of liquid water along the channel, a novel channel design which features multi- outlets and inlets grooved along the cathode channel is proposed as shown in Fig. 14 and Fig. 15. Two mitigation strategies are compared, depending on the numbers of inlet and outlet added. Fig. 14 shows the velocity magnitude inside the electrodes and channels of three channel designs. Due to the relatively high stoichiometry at the cathode, the air flow velocity inside the cathode channel is faster than that of hydrogen at the anode. It is clear that the gas velocity downstream of the new grooved outlets is relatively low. This is mainly explained by the counter flow behavior between the pre-existent and newly introduced gases. Moreover, the newly introduced gases do not affect the overall gas flow direction. The profiles of liquid water saturation inside the channels of three channel designs at $1.2 \mathrm{~A} \mathrm{~cm}^{-2}$ are shown in

Fig. 15. The liquid water saturation at both electrodes is reduced when a multi- inlets and outlets design is applied, which drain the liquid water from the channel and avoid the accumulation of liquid water downstream the channel. The practical multi- air inlets and outlets channel is schematically showed in Fig. 
16. As demonstrated, air flows through the central channel (black one) and the generated liquid water can be diverted through the channel on the right (blue one) after a certain distance, while consumed oxygen in air flow will be replenished using the channel on the left (red one). More inlets and outlets can be added based on the conception indicated in Fig. 16.

\section{Conclusion}

A two-dimensional, along-the-channel, two-phase flow, non-isothermal, agglomerate model was developed to study the distributions of liquid water and heat and catalyst layer effectiveness factors within the MEA and channels for a low temperature PEM fuel cell. Comprehensive water phase-transfer and transport processes were taken into account. Liquid water flooding at the anode side was considered. The model developed was used to study the effects of electrode properties, e.g. contact angle, GDL porosity and thickness, and platinum loading, as well as channel geometries including channel length and depth, on the liquid water distributions inside the MEA and channels. A parametric study was conducted to find out the optimal electrode and channel designs for the maximum current densities at low, medium and high current densities.

The modelling results indicated that the increase in GDL thickness and channel depth lead to a monotonically decrease in cell performance in a large range of current densities while contact angle and channel length almost had no effect on the cell performance at low current densities. At high current densities, liquid water flooding can be mitigated when electrodes with larger contact angle, lower porosity and low platinum loading are used. In the meanwhile, liquid water saturations (volume fraction of liquid water in void space) can be reduced by shorter and deeper flow channels. It was also found that the temperature rise was sharp near the cathode inlet and the temperature slowly increased along the air flow to the outlet. The increase in GDL thickness could mitigate the temperature rise within the MEA but it was at an expense of 
the effectiveness factor of the catalyst layers due to the increased mass transport resistance. The flow channel of $1 \mathrm{~cm}$ was found to be the optimal length to the cell performance at high current densities. A new channel design featured with multi- outlets and inlets along the channel was capable of mitigating the water flooding and improving the cell performance.

\section{Acknowledgement}

The authors gratefully acknowledge the financial support of the Natural Science Foundation of China No. 21546006, the Natural Science Foundation of Jiangsu Province of China No. BK2012701 and BK20150536, and the Engineering and Physical Sciences Research Council (EPSRC) Supergen Fuel Cell Consortium award No. G030995.

\section{References}

Barbir, F., 2005. PEM fuel cells: theory and practice. 2nd ed. Oxford: Academic.

Barelli, L., Bidini, G., Gallorini, F., Ottaviano, A., 2011. Analysis of the operating conditions influence on PEM fuel cell performance by means of a novel semi-empirical model. Int. J. Hydrogen Energy 36, 10434-10442.

Basu, S., Li, J., Wang, C.-Y., 2009. Two-phase flow and maldistribution in gas channels of a polymer electrolyte fuel cell. J Power Sources 187, 431-443.

Bernardi, D.M., Verbrugge, M.W., 1992. A mathematical model of the solid-polymerelectrolyte fuel cell. J. Electrochem. Soc. 139, 2477-2491.

Bird, R.B., Stewart, W.E., Lightfoot, E.N., 2002. Transport phenomena. 2nd ed. John Wiley \& Sons Inc.

Cheddie, D., Munroe, N., 2007. A two phase model of an intermediate temperature PEM fuel cell. Int. J. Hydrogen Energy 32, 832-841.

Chippar, P., Ju, H., 2013. Numerical modeling and investigation of gas crossover effects in high temperature proton exchange membrane (PEM) fuel cells. Int. J. Hydrogen Energy 38, 7704-7714.

Cho, K.T., Mench, M.M., 2012. Investigation of the role of the micro-porous layer in polymer electrolyte fuel cells with hydrogen deuterium contrast neutron radiography. Phys. Chem. Chem. Phys. 14, 42964302. 
Gahleitner, G., 2013. Hydrogen from renewable electricity: an international review of power-to-gas pilot plants for stationary applications. Int. J. Hydrogen Energy 38, 2039-2061.

Ge, S., Wang, C.-Y., 2007. Liquid water formation and transport in the PEFC anode. J. Electrochem. Soc. 154, B998-B1005.

Ge, S., Li, X., Yi, B., Hsing, I.M., 2005. Absorption, desorption, and transport of water in polymer electrolyte membrane for fuel cells. J. Electrochem. Soc. 152, A1149-A1157.

He, W.S., Yi, J.S., Nguyen, T.V., 2000. Two-phase flow model of the cathode of PEM fuel cells using interdigitated flow field. AIChE J. 46, 2053-2064.

Holdcroft, S., 2014. Fuel cell catalyst layer: A polymer science perspective. Chem. Mater. 26, 381-393.

Iranzo, A., Boillat, P., Biesdorf, J., Salva, A., 2015. Investigation of the liquid water distribution in a $50 \mathrm{~cm}^{2}$ PEM fuel cell: Effects of reactants relative humidity, current density, and cathode stoichiometry. Energy $82,914-921$.

Ismail, M.S., Hughes, K.J., Ingham, D.B., Ma, L., Pourkashanian, M., 2012. Effect of anisotropic permeability and electrical conductivity of gas diffusion layers on the performance of proton exchange membrane fuel cells. Appl. Energy 95, 50-63.

Ju, H., Meng, H., Wang, C.-Y., 2005. A single-phase, non-isothermal model for PEM fuel cells. Int. J. Heat Mass Transfer 48, 1303-1315.

Kamarajugadda, S., Mazumder, S., 2008. Numerical investigation of the effect of cathode catalyst layer structure and composition on polymer electrolyte membrane fuel cell performance. J. Power Sources $183,629-642$.

Kestin, J., Sokolov, M., Wakeham, W.A., 1978 . Viscosity of liquid water in the range $-8^{\circ} \mathrm{C}$ to $150^{\circ} \mathrm{C}$. J. Phys. Chem. Ref. Data 7, 941-948.

Khajeh-Hosseini-Dalasm, N., Kermani, M.J., Moghaddam, D.G., Stockie, J.M., 2010. A parametric study of a PEM fuel cell. Int. J. Hydrogen Energy 35, 2417-2427.

Khajeh-Hosseini-Dalasm, N., Fesanghary, M., Fushinobu, K., Okazaki, K., 2012. A study of the agglomerate catalyst layer for the cathode side of a proton exchange membrane fuel cell: modelling and optimization. Electrochim. Acta 60, 55-65.

Kumar, R., Scott, K., 2012. Freestanding sulfonated grapheme oxide paper: a new polymer electrolyte for polymer electrolyte fuel cells. Chem. Commn. 48, 5584-5586.

Lampinen, M.J., Fomino, M., 1993. Analysis of free energy and entropy changes for half-cell reactions. J. 
Electrochem. Soc. 140, 3537-3546.

Lund, H., Andersen, A.N., Østergaard, P.A., Mathiesen, B.V., Connolly, D., 2012. From electricity smart grids to smart energy systems - A market operation based approach and understanding. Energy 42, 96102.

Marr, C., Li, X., 1999. Composition and performance modelling of catalyst layer in a proton exchange membrane fuel cell. J. Power Sources 77, 17-27.

Mason, T.J., Millichamp, J., Neville, T.P., Shearing, P.R., Simons, S., Brett, D.J.L., 2013. A study of the effect of water management and electrode flooding on the dimensional change of polymer electrolyte fuel cells. J. Power Sources 242, 70-77.

Nam, J.H., Kaviany, M., 2003. Effective diffusivity and water-saturation distribution in single- and twolayer PEMFC diffusion medium. Int. J. Heat Mass Transfer 46, 4595-4611.

Nguyen, T.V., White, R.E., 1993. A water and heat management model for proton-exchange-membrane fuel cells. J. Electrochem. Soc. 140, 2178-2186.

Pasaogullari, U., Wang, C.-Y., 2004a. Liquid water transport in gas diffusion layer of polymer electrolyte fuel cells. J. Electrochem. Soc. 151, A399-A406.

Pasaogullari, U., Wang, C.-Y., 2004b. Two-phase transport and the role of micro-porous layer in polymer electrolyte fuel cells. Electrochim. Acta 49, 4359-4369.

Park, S., Lee, J.-W., Popov, B.N., 2008. Effect of PTFE content in microporous layer on water management in PEM fuel cells. J. Power Sources 177, 457-463.

Park, S., Lee, J.-W., Popov, B.N., 2012. A review of gas diffusion layer in PEM fuel cells: Materials and designs. Int. J. Hydrogen Energy 37, 5850-5865.

Shimpalee, S., Beuscher, U., Van Zee, J.W., 2007. Analysis of GDL flooding effects on PEMFC performance. Electrochim. Acta 52, 6748-6754.

Shah, A.A., Kim, G.S., Sui, P.C., Harvey, D., 2007. Transient non-isothermal model of a polymer electrolyte fuel cell. J. Power Sources 163, 793-1806.

Sousa, T., Mamlouk, M., Scott, K., 2010. An isothermal model of a laboratory intermediate temperature fuel cell using PBI doped phosphoric acid membranes. Chem. Eng. Sci. 65, 2513-2530.

Sun, W., Peppley, B.A., Karan. K., 2005. An improved two-dimensional agglomerate cathode model to study the influence of catalyst layer structural parameters. Electrochim. Acta 50, 3359-3374.

Wang, C.-Y., Cheng, P., 1996. A multiphase mixture model for multiphase, multicomponent transport in 
capillary porous media - I. Model development. Int. J. Heat Mass Transfer 36, 3607-3618.

Wang, L., Husar, A., Zhou, T., Liu, H., 2003. A parametric study of PEM fuel cell performances. Int J Hydrogen Energy 28, 1263-1272.

Wang, Y., Chen, K.S., Mishler, J., Cho, S.C., Adroher, X.C., 2011. A review of polymer electrolyte membrane fuel cells: Technology, applications, and needs on fundamental research. Appl. Energy 88, 981-1007.

Wang, Z.H., Wang, C.-Y., Chen, K.S., 2001. Two-phase flow and transport in the air cathode of proton exchange membrane fuel cells. J. Power Sources 64, 40-50.

Weber, A.Z., Newman. J., 2005. Effects of microporous layers in polymer electrolyte fuel cells. J. Electrochem. Soc. 152, A677-A688.

Weber, A.Z., Newman, J., 2006. Coupled thermal and water management in polymer electrolyte fuel cells. J. Electrochem. Soc. 153, A2205-A2214.

Wilke, C.R., 1950. A viscosity equation for gas mixture. J. Chem. Phys. 18, 517-519.

Wong, K.H., Loo K.H., Lai Y.M., Tan S.C., Tse C.K., 2011. A theoretical study of inlet relative humidity control in PEM fuel cell. Int. J. Hydrogen Energy 36, 11871-11885.

Wu, H., Berg, P., Li, X., 2010a. Modelling of PEMFC transients with finite-rate phase transfer processes. J. Electrochem. Soc. 157, B1-B12.

Wu, H., Berg, P., Li, X., 2010b. Steady and unsteady 3D non-isothermal modelling of PEM fuel cells with the effect of non-equilibrium phase transfer. Appl Energy 87, 2778-2784.

Xing, L., Mamlouk, M., Scott, K., 2013a. A two dimensional agglomerate model for a proton exchange membrane fuel cell. Energy 61, 196-210.

Xing, L., Song, X., Scott, K., Pickert, V., Cao, W., 2013b. Multi-variable optimisation of PEMFC cathodes based on surrogate modelling. Int. J. Hydrogen Energy 38, 14295-14313.

Xing, L., Liu, X., Alaje, T., Kumar, R., Mamlouk, M., Scott, K., 2014a. A two-phase flow and nonisothermal agglomerate model for a proton exchange membrane (PEM) fuel cell. Energy 73, 618-634.

Xing, L., Mamlouk, M., Kumar, R., Scott, K., 2014b. Numerical investigation of the optimal Nafion ionomer content in cathode catalyst layer: An agglomerate two-phase flow modelling. Int. J. Hydrogen Energy 39: 9087-9104.

Xing, L., Das, P.K., Song, X., Mamlouk, M., Scott, K., 2015. Numerical analysis of the optimum membrane/ionomer water content of PEMFCs: The interaction of Nafion ionomer content and cathode 
relative humidity. Appl. Energy 138, 242-257.

Xing, L., Du, S., Chen, R., Mamlouk, M., Scott, K., 2016. Anode partial flooding modelling of proton exchange membrane fuel cells: Model development and validation. Energy 96, 80-95.

Yang, X.G., Ye, Q., Cheng, P., 2011. Matching of water and temperature fields in proton exchange membrane fuel cells with non-uniform distributions. Int. J. Hydrogen Energy 36, 12524-12537.

Yi, J.S., Nguyen, T.V., 1998. An along-the-channel model for proton exchange membrane fuel cells. J. Electrochem. Soc. 145, 1149-1159.

Zhou, Y., Lin, G., Shih, A.J., Hu, S.J., 2009. Assembly pressure and membrane swelling in PEM fuel cells. J. Power Sources 192, 544-551.

\section{Nomenclature}

$\begin{array}{ll}A_{M} & \text { effective area of electrode, } \mathrm{m}^{2} \\ A_{c h} & \text { cross-sectional area of channel, } \mathrm{m}^{2} \\ a & \text { specific area, } \mathrm{m}^{-1} \\ c_{p, i} & \text { specific heat capacity of species } i, \mathrm{~J} \mathrm{~mol}^{-1} \mathrm{~K}^{-1} \\ c & \text { concentration, mol m} \mathrm{m}^{-3} \\ D & \text { diffusivity, } \mathrm{m}^{2} \mathrm{~s}^{-1}\end{array}$




\begin{tabular}{|c|c|}
\hline$D_{c}$ & capillary diffusion coefficient, $\mathrm{m}^{2} \mathrm{~s}^{-1}$ \\
\hline$D_{i j}$ & Maxwell-Stefan diffusion coefficient matrix, $\mathrm{m}^{2} \mathrm{~s}^{-1}$ \\
\hline$E$ & effectiveness factor \\
\hline$E^{0}$ & open circuit potential, $\mathrm{V}$ \\
\hline$E_{\text {cell }}$ & cell voltage, $\mathrm{V}$ \\
\hline$E W$ & ionomer equivalent weight, $\mathrm{g} \mathrm{mol}^{-1}$ \\
\hline$F$ & Farady's constant, $96485 \mathrm{C} \mathrm{mol}^{-1}$ \\
\hline$H$ & Henry's constant, $\mathrm{Pa} \mathrm{m}^{3} \mathrm{~mol}^{-1}$ \\
\hline$i$ & current density, $\mathrm{A} \mathrm{m}^{-2}$ \\
\hline$i_{0}$ & exchange current density, $\mathrm{A} \mathrm{m}^{-2}$ \\
\hline$J(\mathrm{~s})$ & Leverett function \\
\hline$k$ & rate coefficient, $\mathrm{s}^{-1}$ \\
\hline$k_{i}$ & Thermal conductivity of species $i, \mathrm{~W} \mathrm{~m}^{-1} \mathrm{~K}^{-1}$ \\
\hline$k_{r}$ & relative permeability \\
\hline$k_{p}$ & hydraulic permeability, $\mathrm{m}^{2}$ \\
\hline$L$ & length, $\mathrm{m}$ \\
\hline$M_{j}$ & molecular weight for specie $\mathrm{j}, \mathrm{kg} \mathrm{mol}^{-1}$ \\
\hline$M_{T}$ & Thieles's modulus \\
\hline$n$ & number of electron involved \\
\hline$p$ & pressure, $\mathrm{Pa}$ \\
\hline$R$ & ideal gas constant, $8.314 \mathrm{~J} \mathrm{~mol}^{-1} \mathrm{~K}^{-1}$ \\
\hline$R H$ & relative humidity \\
\hline
\end{tabular}


Greek

$\alpha$

$\alpha_{w}$

$\lambda$

$\mu$

$\rho$

$\varepsilon$

$\delta$

$\gamma$

$\eta$

$\sigma$

$\xi$

$\theta_{c}$ source term

liquid water saturation

temperature, $\mathrm{K}$

velocity vector, $\mathrm{m} \mathrm{s}^{-1}$

mass fraction

normalised distance $(x / \delta)$

mole fraction

normalised distance $(y / L)$

volume fraction of primary pores occupied by ionomer

charge transfer coefficient

water activity

water content

viscosity, Pa s

density, $\mathrm{kg} \mathrm{m}^{-3}$

porosity

thickness/depth, $\mathrm{m}$

hydrogen/oxygen diffusion rate through the film, $\mathrm{s}^{-1}$

overpotential, $\mathrm{V}$

surface tension, $\mathrm{N} \mathrm{m}^{-1}$

Stoichiometric flow ratio

contact angel, ${ }^{\circ}$ 
$\sigma_{\mathrm{S}}$

$\sigma_{\mathrm{M}}$

$\varphi$

\section{Superscripts}

0

eff

ref

$e q$

$l$

$g$

Subscripts

$a$

ads

agg

C

c

$C L$

des

$G D L$

$i$

$j$ electronic conductivity, $\mathrm{S} \mathrm{m}^{-1}$

ionic conductivity, $\mathrm{S} \mathrm{m}^{-1}$

potential, $\mathrm{V}$

intrinsic

dissolved

effective

reference

equilibrium

liquid

gas

anode

adsorption

agglomerate

carbon

cathode

catalyst layer

desorption

gas diffusion layer

species i

species j 


$\begin{array}{ll}M & \text { Membrane/ionomer } \\ r & \text { relative } \\ T & \text { temperature } \\ w & \text { liquid water } \\ s a t & \text { saturation } \\ \text { tot } & \text { total } \\ v l & \text { vapour to liquid } \\ v d & \text { vapour to dissolved } \\ d l & \text { dissolved to liquid }\end{array}$

\section{Figure 1}

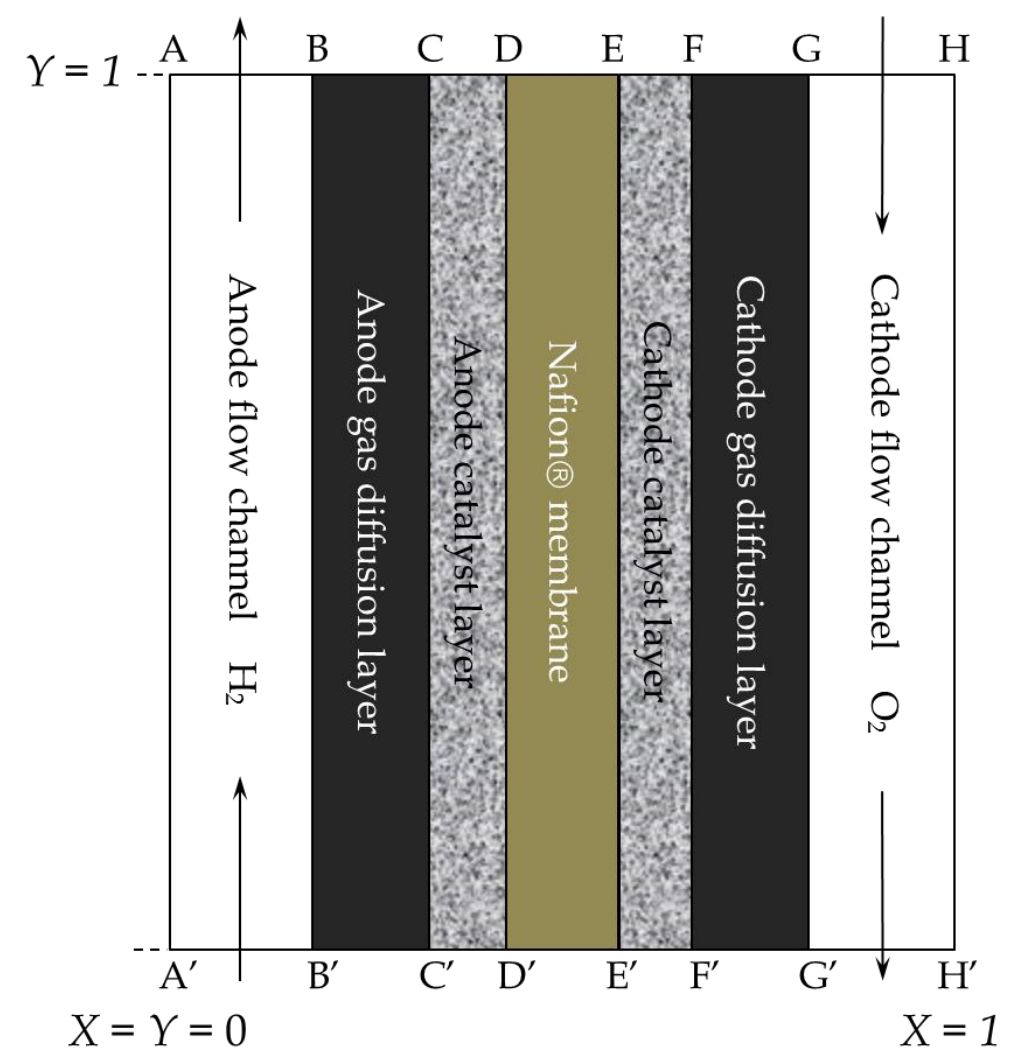


Fig. 1 Sketch and computation domain of a PEM fuel cell

\section{Figure 2}




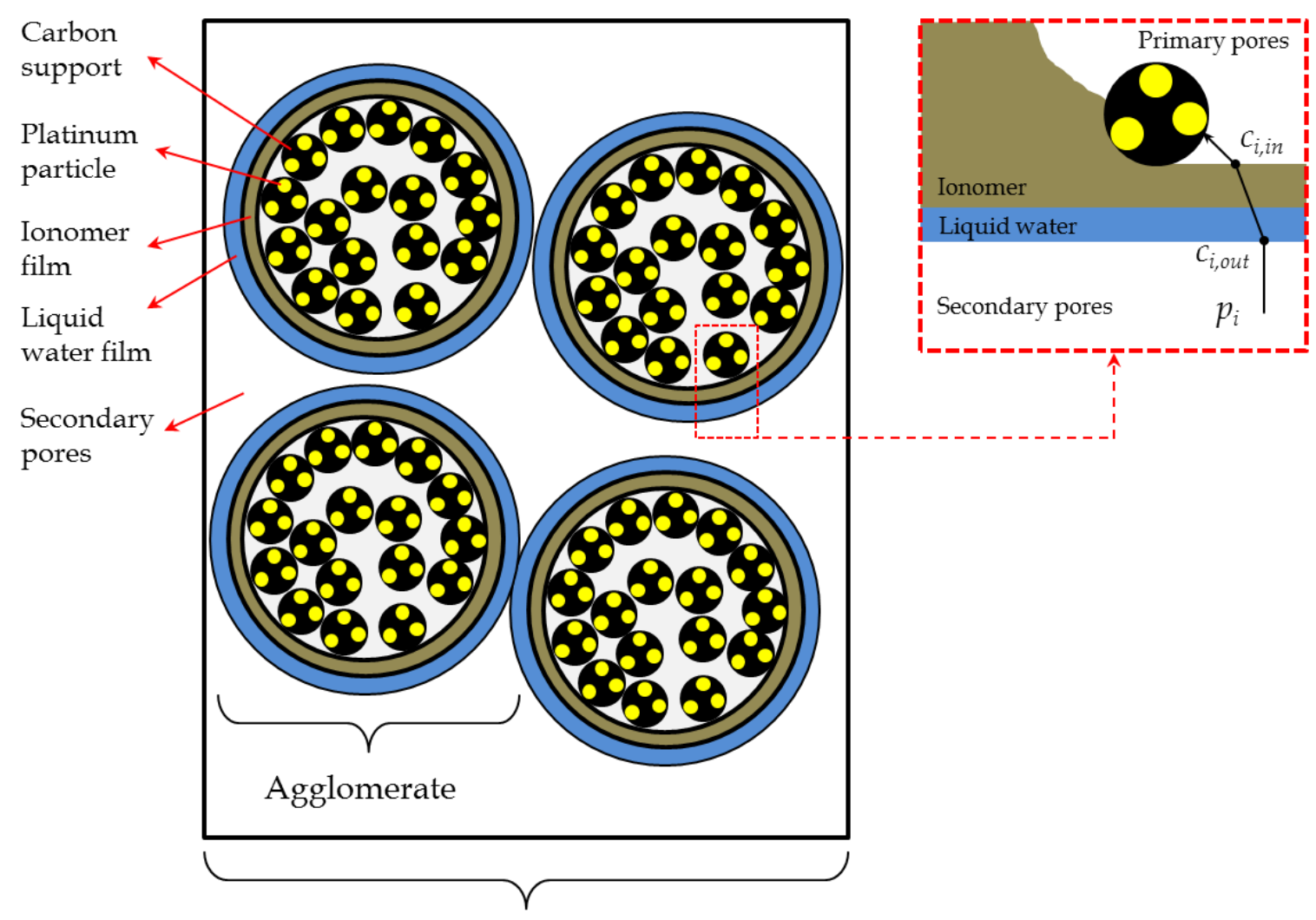

Catalyst layer

Fig. 2 Schematic representation of catalyst layer and reactant gas diffusion through the ionomer film surrounding the agglomerate

\section{Figure 3}




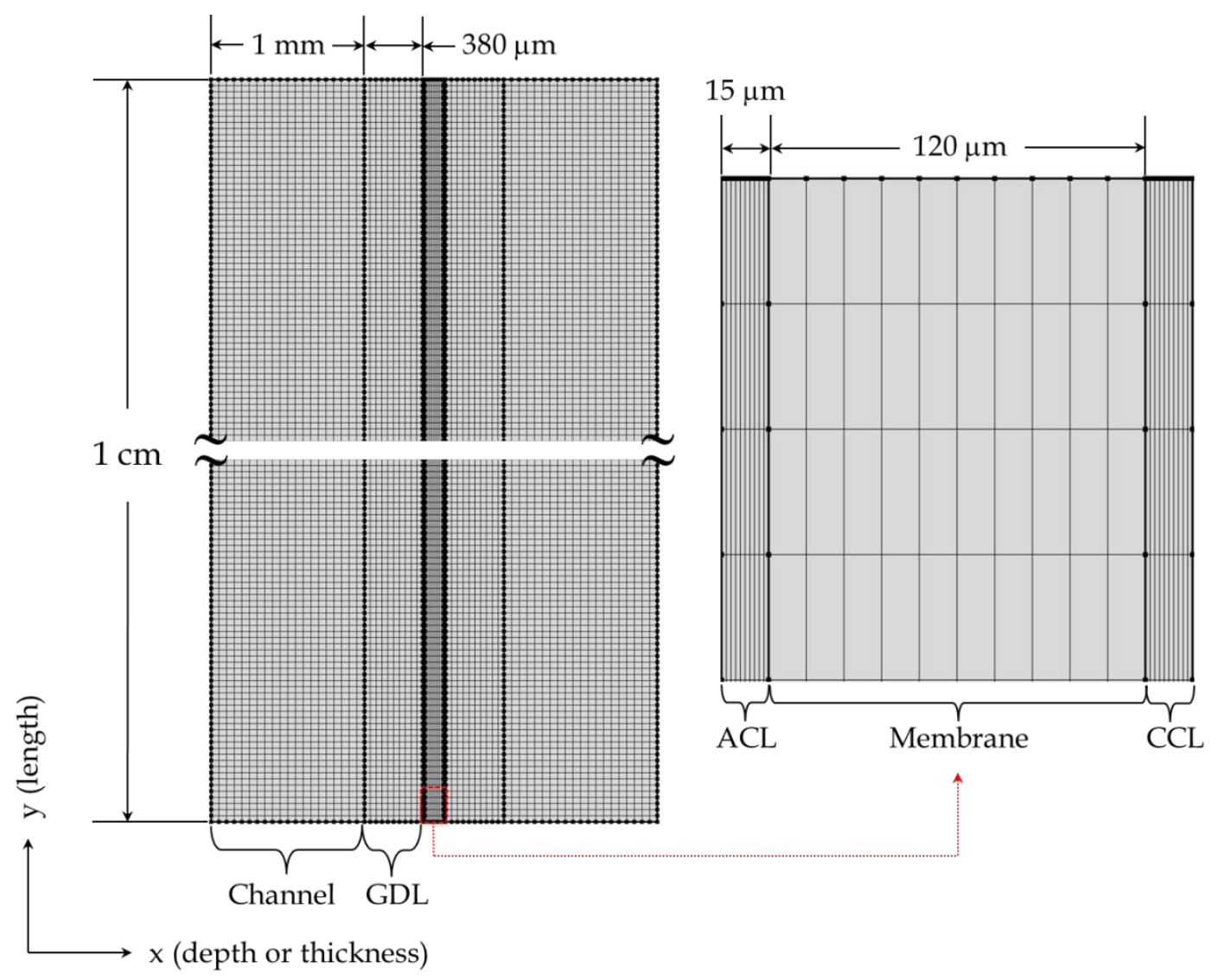

Fig. 3 Geometry properties and mesh characters of the studied PEM fuel cell

Figure 4 


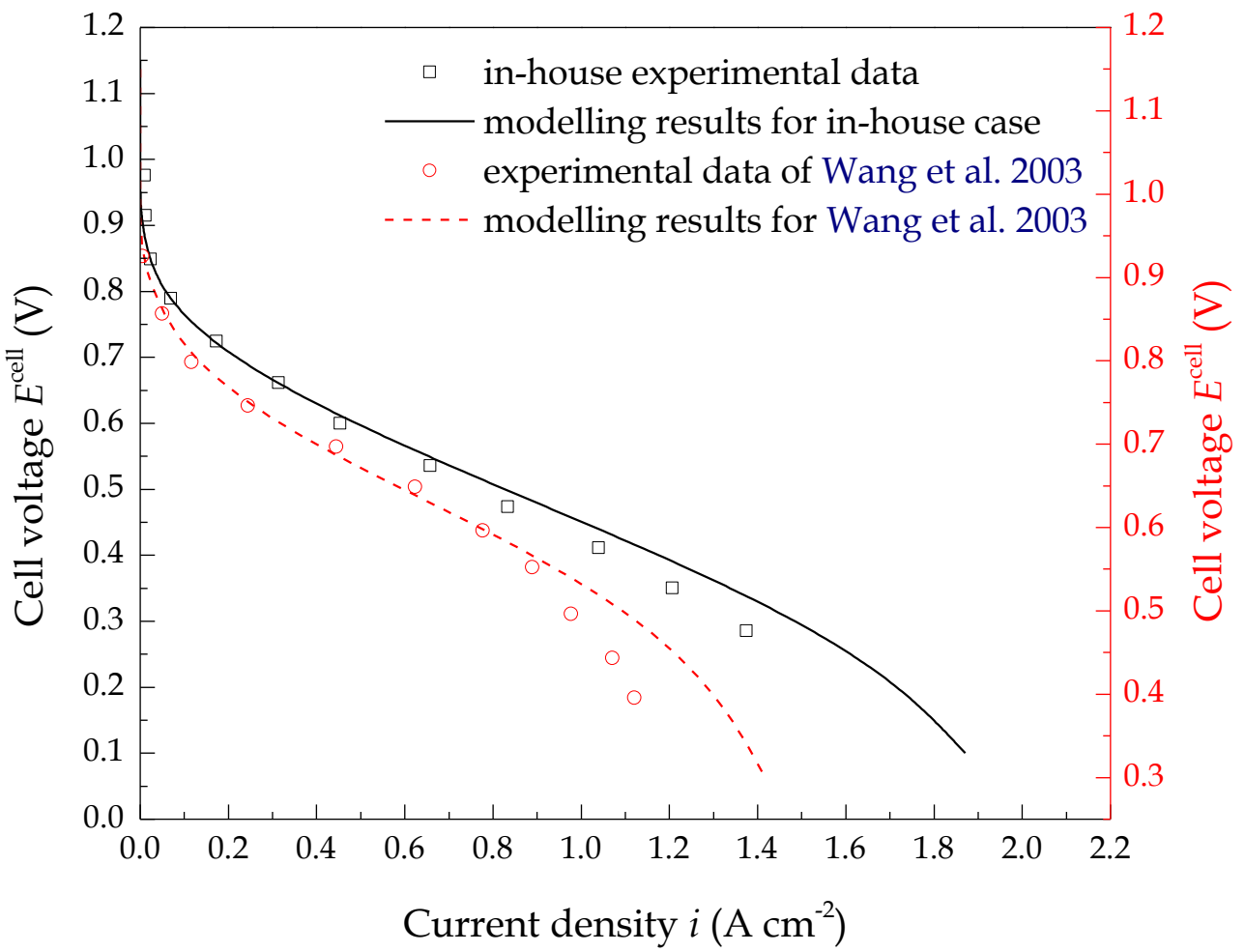

Fig. 4 Comparison of modelling results with experimental data for two cases

In-house: $80^{\circ} \mathrm{C}, 20 \% \mathrm{Pt} / \mathrm{C}, m_{\mathrm{Pt}, \mathrm{a}}=0.1 \mathrm{mg} \mathrm{cm}^{-2}, m_{\mathrm{Pt}, \mathrm{c}}=0.4 \mathrm{mg} \mathrm{cm}^{-2}$, Nafion 112 membrane, effective area: $1.0 \mathrm{~cm} \times 1.0 \mathrm{~cm}$,

channel width and depth: $1 \mathrm{~mm}$; Wang et al. (2003): $70{ }^{\circ} \mathrm{C}, 40 \% \mathrm{Pt} / \mathrm{C}, m_{\mathrm{Pt}, \mathrm{a}}=m_{\mathrm{Pt}, \mathrm{c}}=0.4 \mathrm{mg} \mathrm{cm}^{-2}$, effective area: $7.2 \mathrm{~cm} \times 7.2$

$\mathrm{cm}$, channel width and depth: $1 \mathrm{~mm}$. For both cases: $R H=100 \%$, pressure: $1.0 \mathrm{~atm}$.

\section{Figure 5}




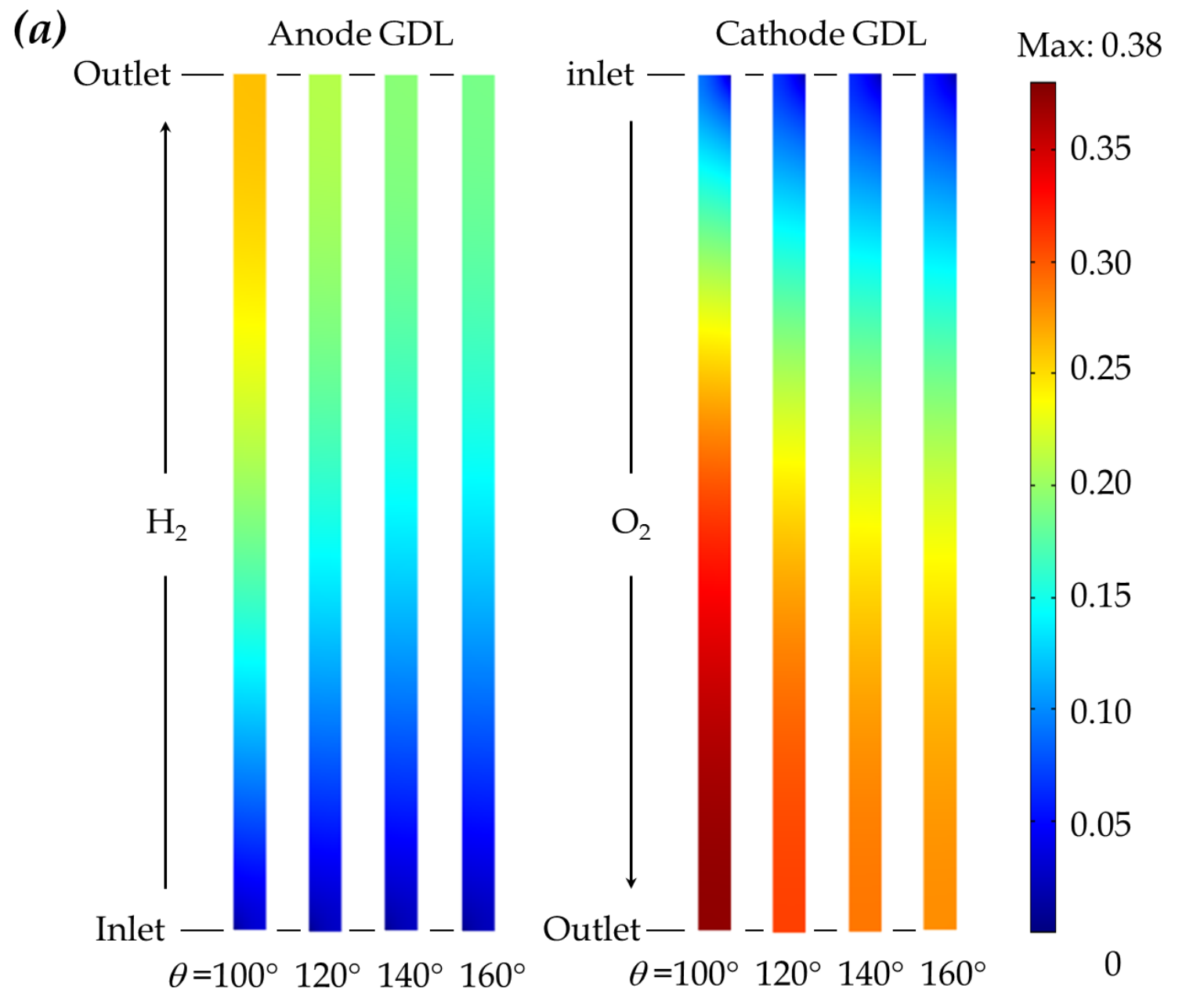




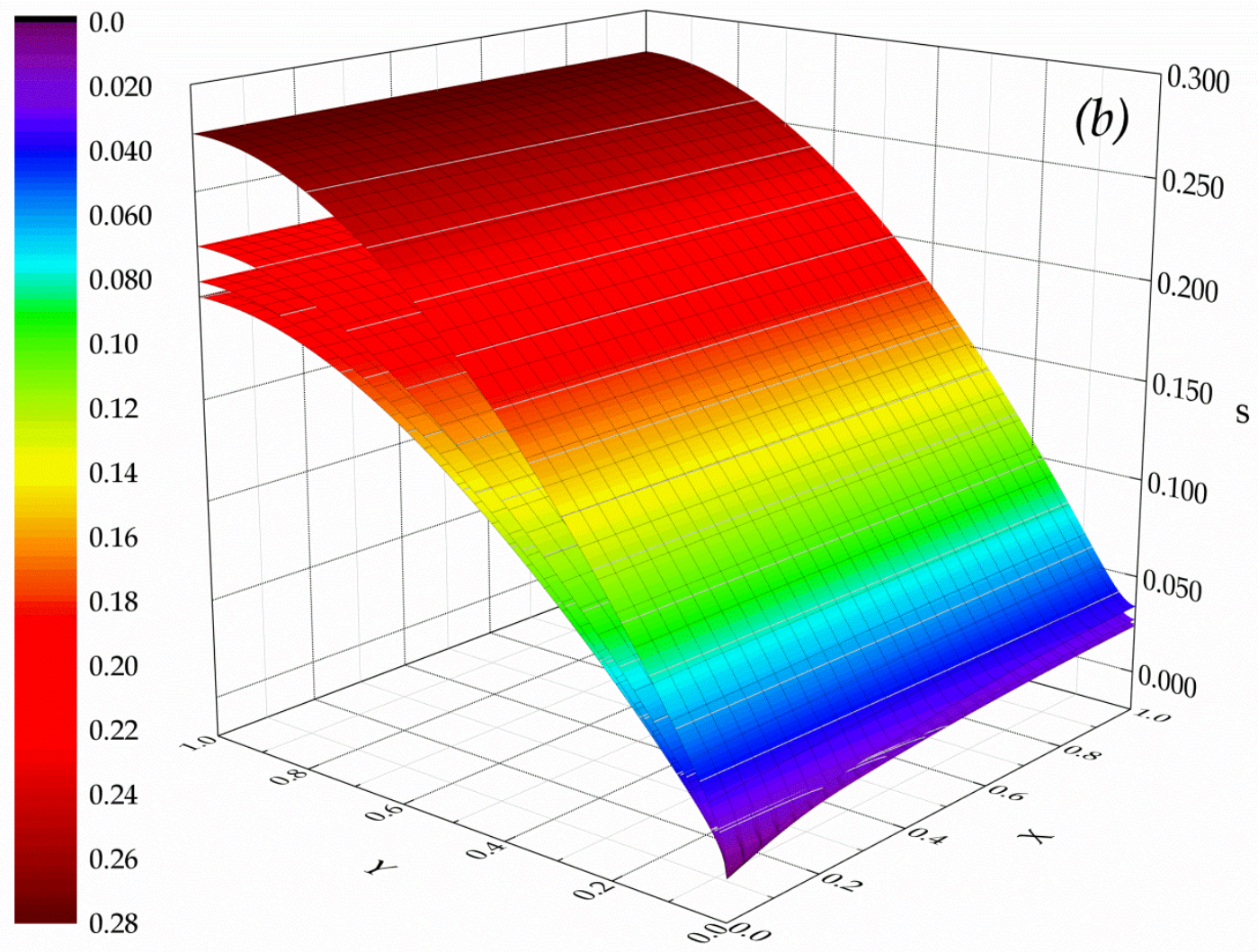




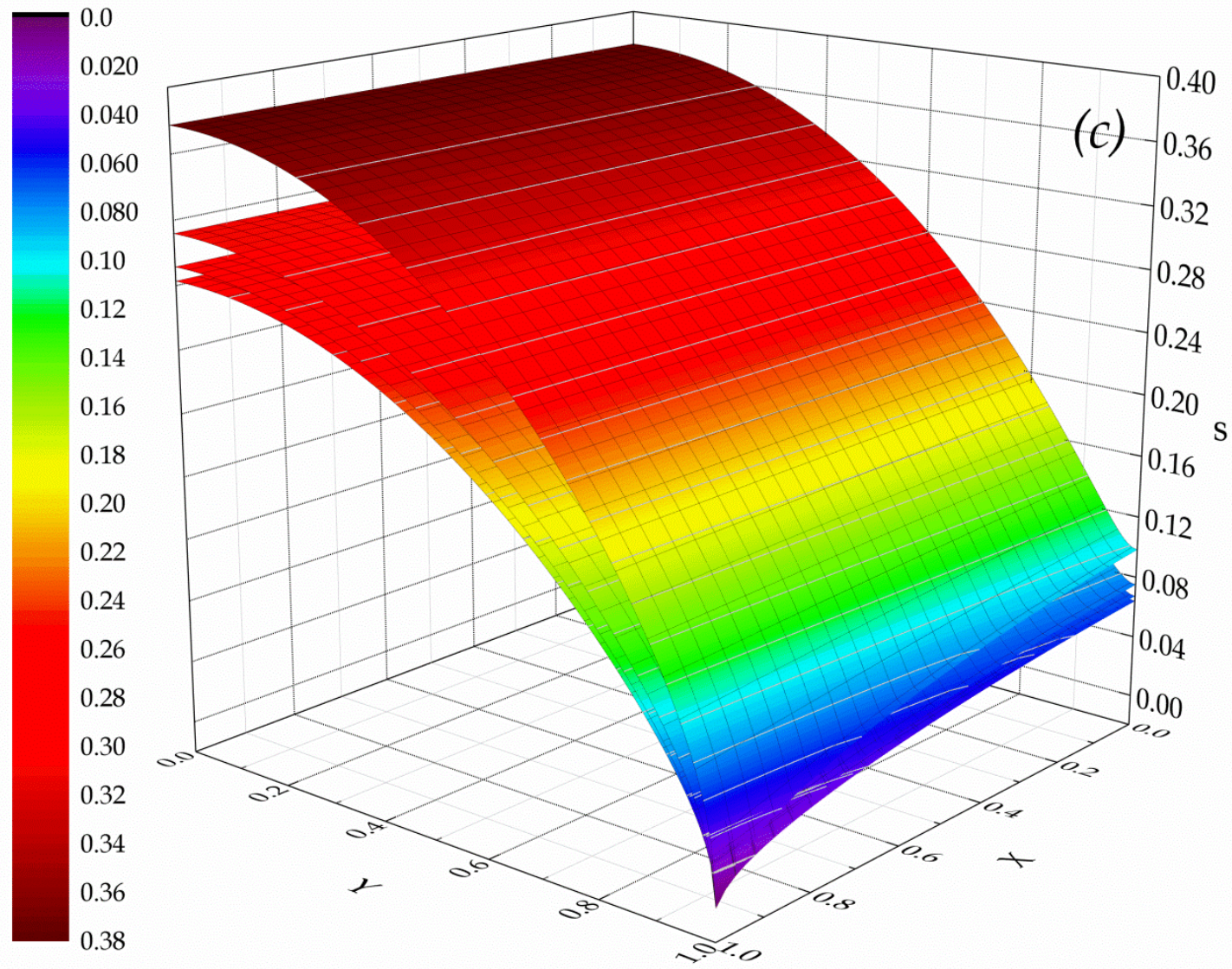

Fig. 5 Dimensional liquid water saturation in (a) anode and cathode GDLs and dimensionless liquid water saturation in (b) anode GDL and (c) cathode GDL with various contact angels at $0.3 \mathrm{~V}$ in base-case condition: $\theta=100^{\circ}, 120^{\circ}, 140^{\circ}$ and $160^{\circ}$ from up down. $\mathrm{X}$ and $\mathrm{Y}$ are the dimensionless through-plane and in-plane directions. Boundaries $\mathrm{X}=0$ - anode channel-GDL interface in Fig. 5b and cathode GDL-CL interface in Fig. 5c; X=1 - anode GDL-CL interface in Fig. 5b and cathode channel-GDL interface in Fig. 5c; Y=0 - anode gas inlet in Fig. 5b and cathode gas outlet in Fig. 5c; Y=1 - anode gas outlet in Fig. 5b and cathode gas inlet in Fig. 5c. 


\section{Figure 6}
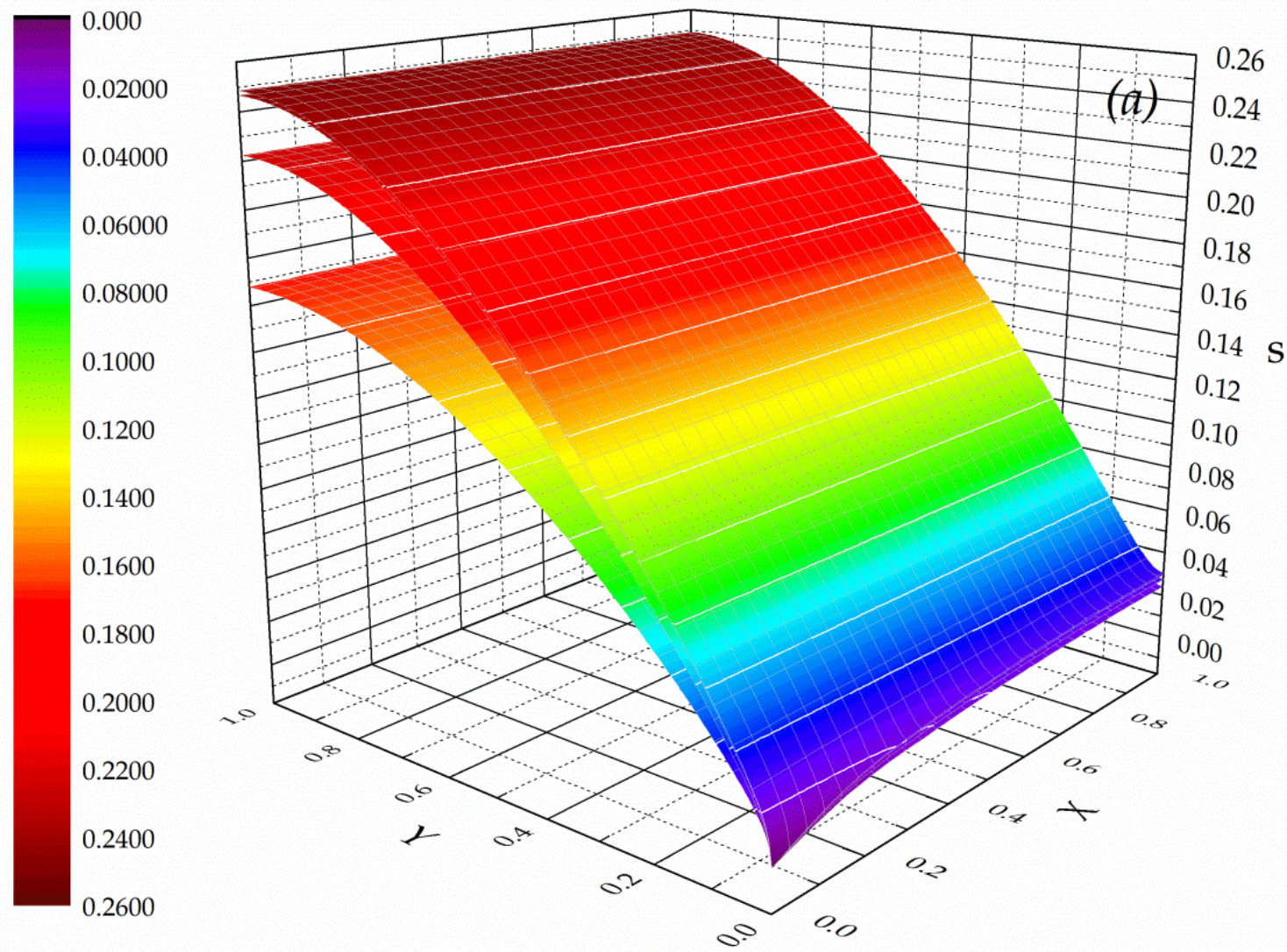

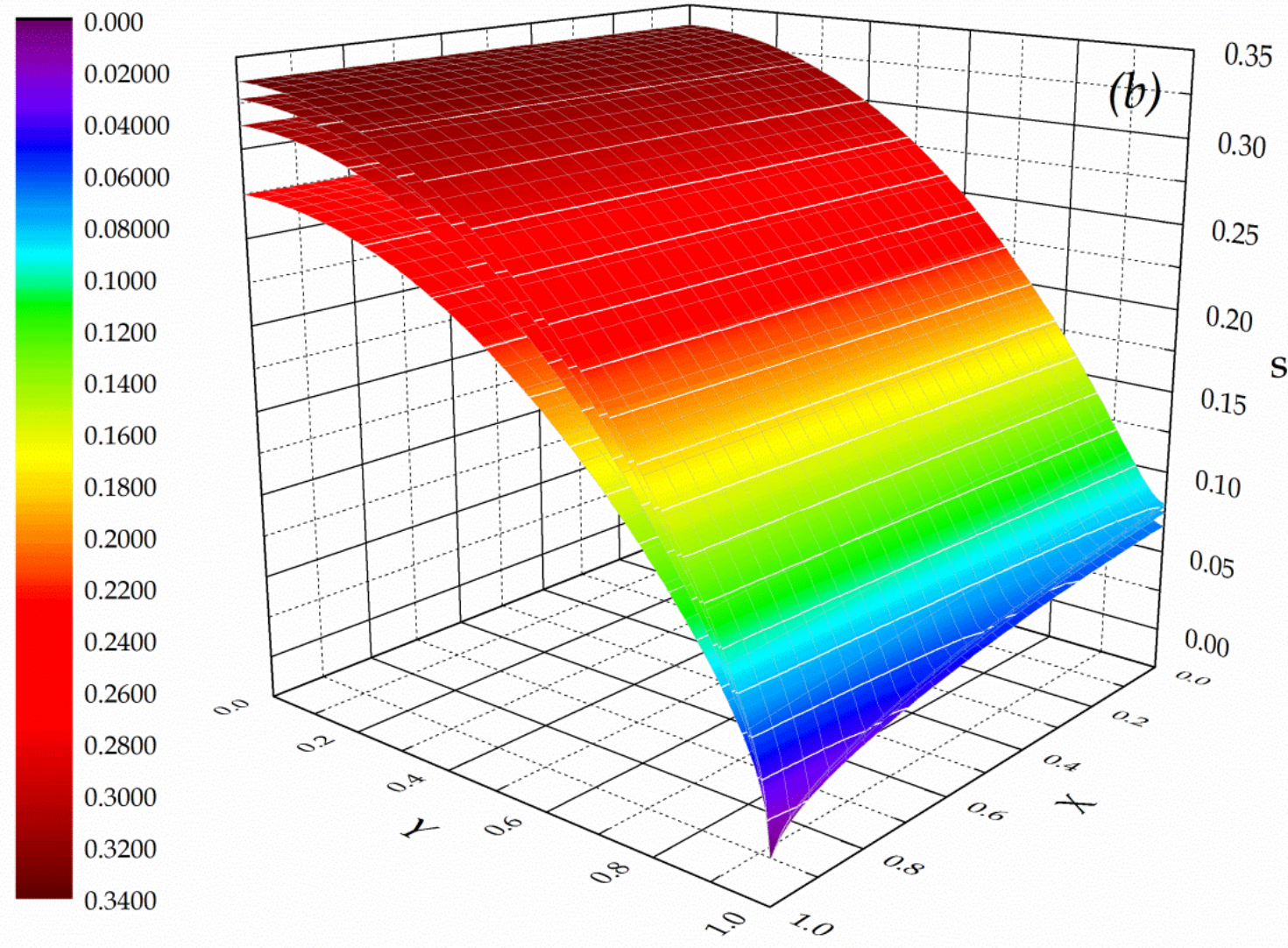

Fig. 6 Liquid water saturation in (a) anode GDL and (b) cathode GDL with various GDL porosities at $0.3 \mathrm{~V}$ in base-case condition: $\varepsilon_{\mathrm{GDL}}=80 \%, 60 \%, 40 \%$ and $20 \%$ from up down. $\mathrm{X}$ and $\mathrm{Y}$ are the dimensionless through-plane and in-plane directions. Boundaries $\mathrm{X}=0$ - anode channel-GDL interface in Fig. 6a and cathode GDL-CL interface in Fig. 6b; X=1 - anode GDL-CL interface in Fig. 6a and cathode channel-GDL interface in Fig. 6b; Y=0 - anode gas inlet in Fig. 6a and cathode gas outlet in Fig. 6b; Y=1 - anode gas outlet in Fig. 6a and cathode gas inlet in Fig. 6b. 


\section{Figure 7}

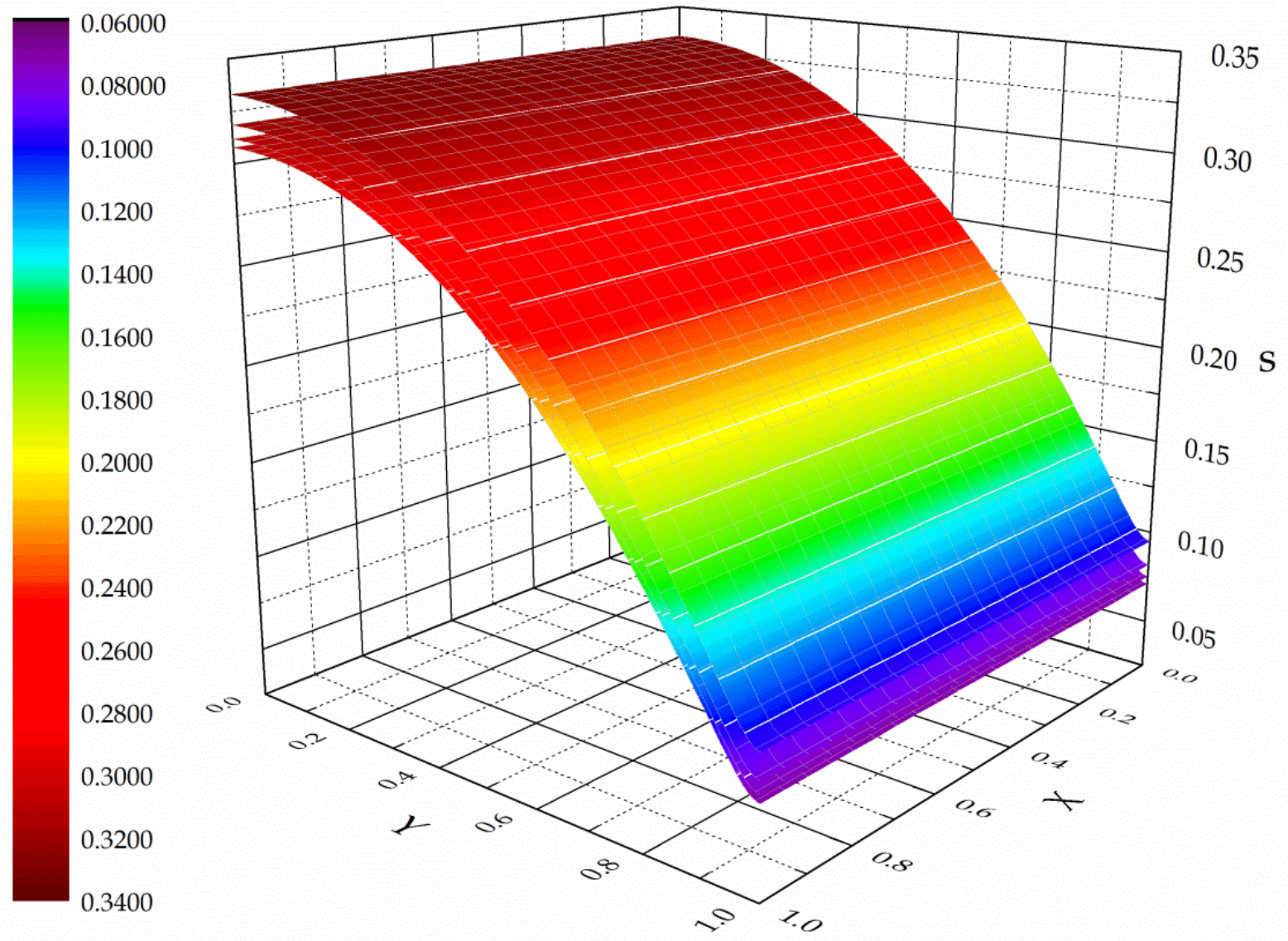

Fig. 7 Liquid water saturation in CCL with various platinum loadings at $0.3 \mathrm{~V}$ in base-case condition: $m_{\mathrm{Pt}}=$ $0.8,0.6,0.4$ and $0.2 \mathrm{mg} \mathrm{cm}^{-2}$ from up down. $\mathrm{X}$ and $\mathrm{Y}$ are the dimensionless through-plane and in-plane directions. Boundaries $\mathrm{X}=0$ - cathode membrane-CL interface; $\mathrm{X}=1$ - cathode GDL-CL interface; $\mathrm{Y}=0$ cathode gas outlet; $\mathrm{Y}=1$ - cathode gas inlet. 


\section{Figure 8}

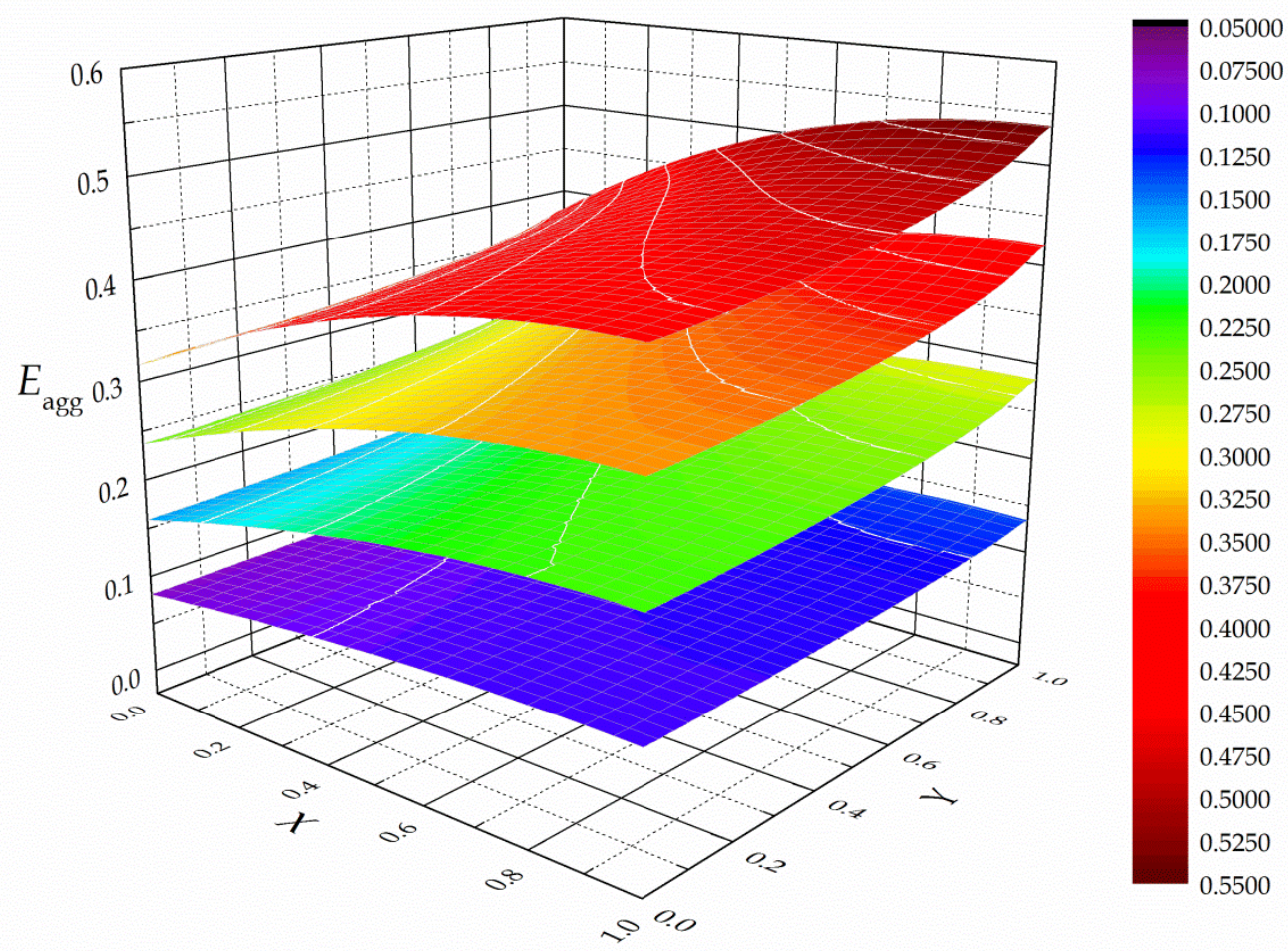

Fig. $8 \mathrm{CCL}$ effectiveness factor with various platinum loadings at $0.3 \mathrm{~V}$ in base-case condition: $\mathrm{m}_{\mathrm{Pt}}=0.2$, $0.4,0.6$ and $0.8 \mathrm{mg} \mathrm{cm}^{-2}$ from up down. $\mathrm{X}$ and $\mathrm{Y}$ are the dimensionless through-plane and in-plane directions. Boundaries $\mathrm{X}=0$ - cathode membrane-CL interface; $\mathrm{X}=1$ - cathode GDL-CL interface; $\mathrm{Y}=0$-cathode gas outlet; $\mathrm{Y}=1$ - cathode gas inlet. 


\section{Figure 9}

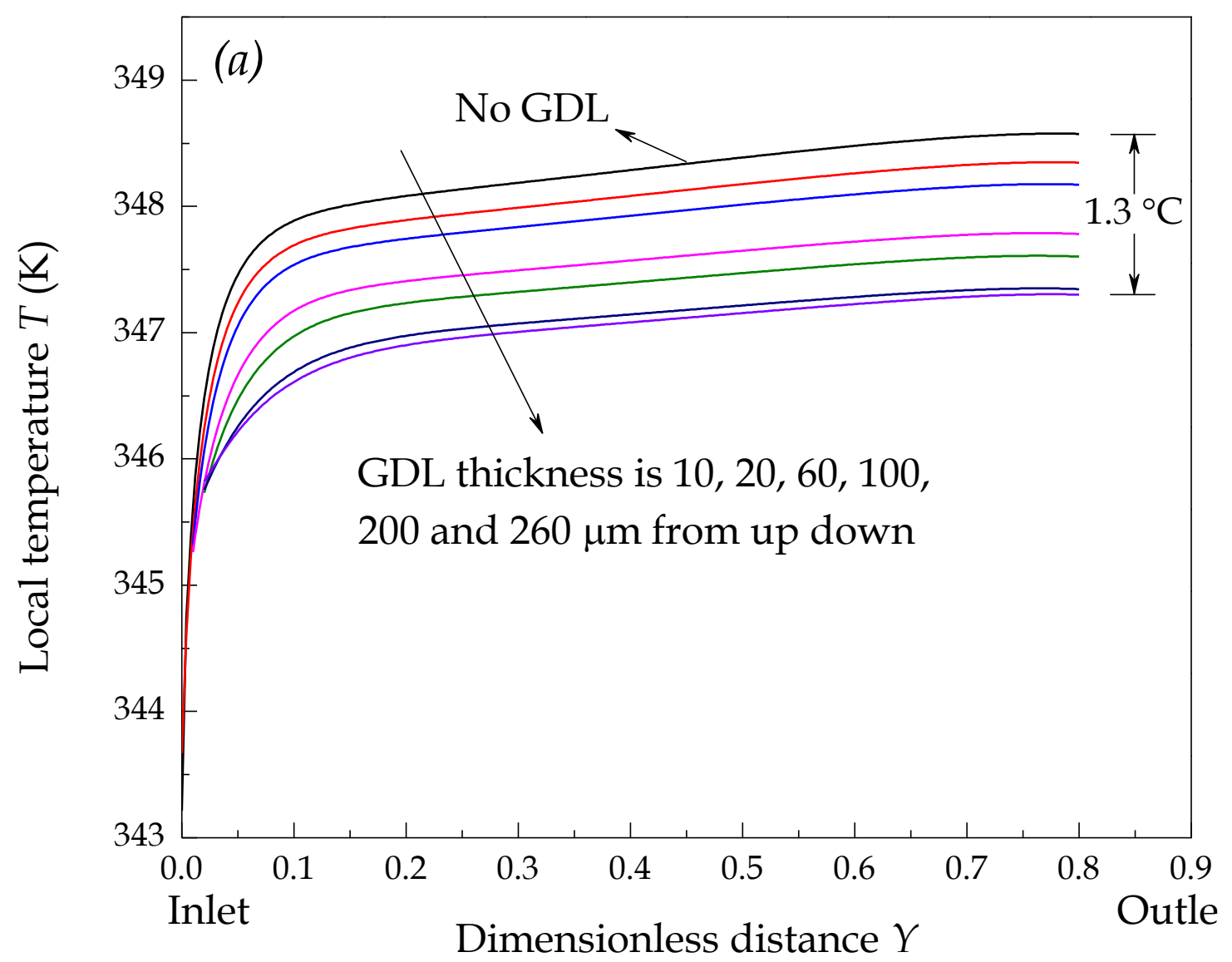




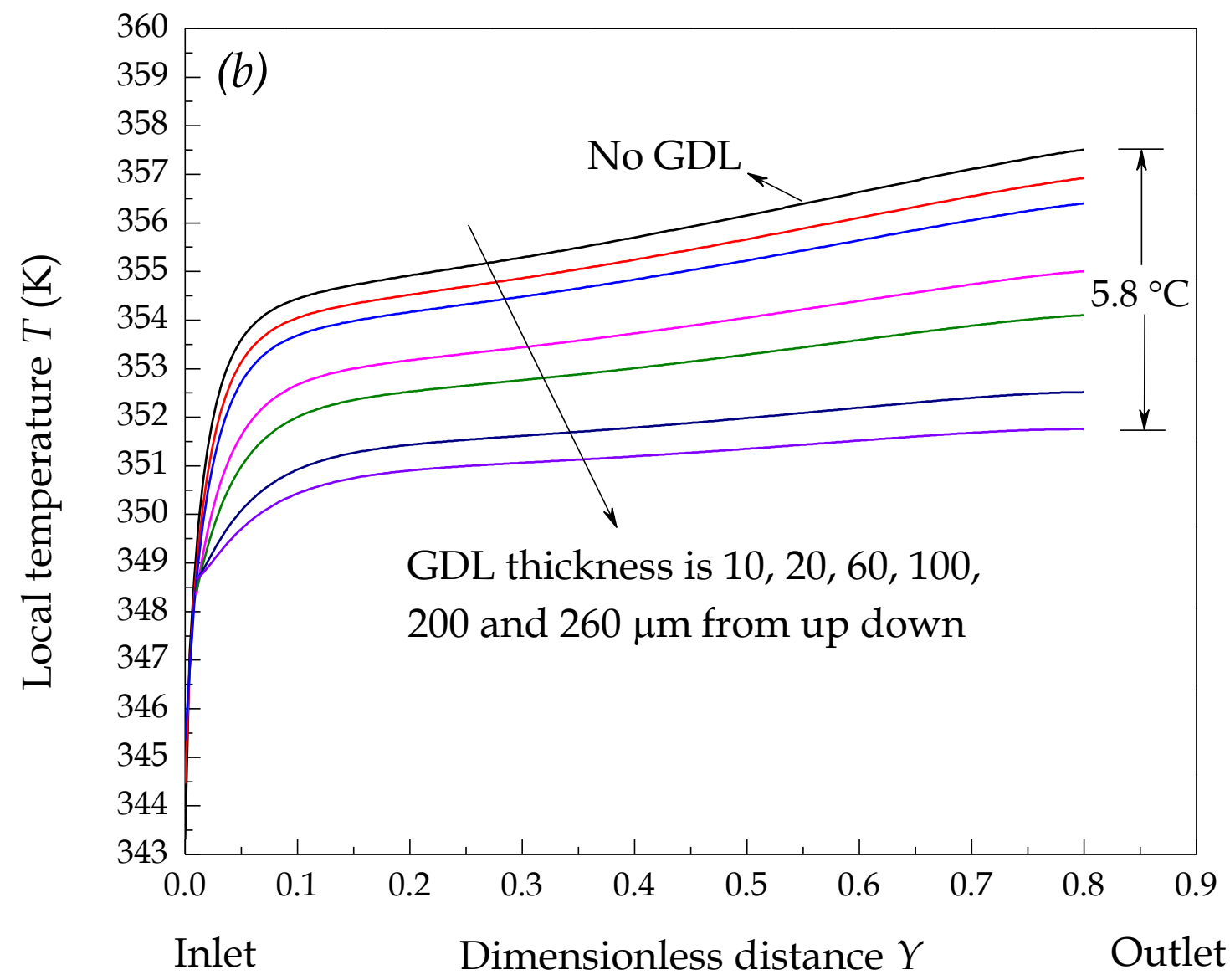

Fig. 9 Temperature profile at cathode CL-GDL interface at the cell voltages of (a) $0.4 \mathrm{~V}$ (b) $0.1 \mathrm{~V}$ with various GDL thickness in base-case condition: $\delta_{\mathrm{GDL}}=10,20,60,100,200$ and $260 \mu \mathrm{m}$ from up down. 


\section{Figure 10}

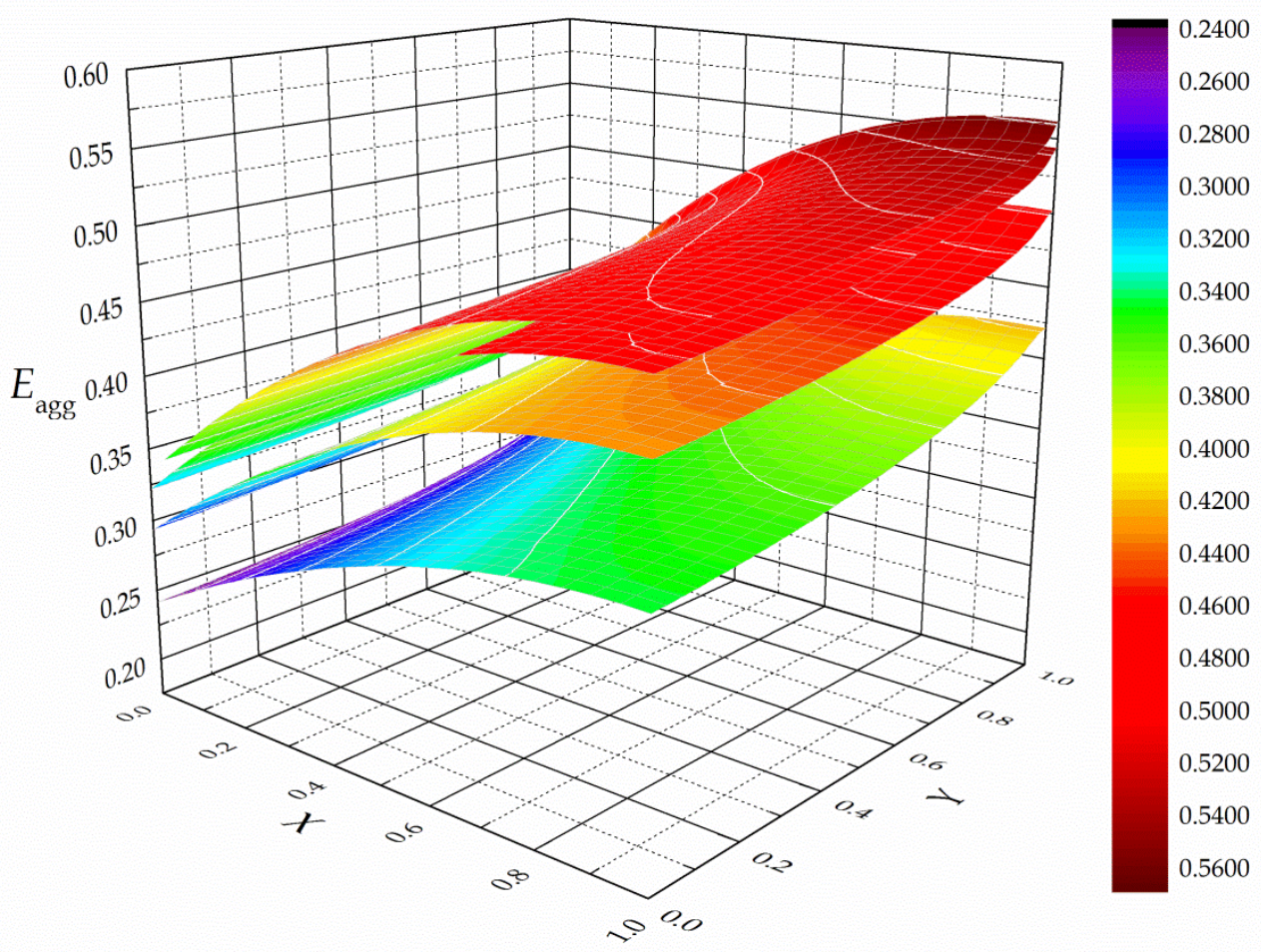

Fig. $10 \mathrm{CCL}$ effectiveness factor with various GDL thicknesses at $0.3 \mathrm{~V}$ in base-case condition: $\delta_{\mathrm{GDL}}=60$, 100, 200 and $380 \mu \mathrm{m}$ from up down. $\mathrm{X}$ and $\mathrm{Y}$ are the dimensionless through-plane and in-plane directions. Boundaries $\mathrm{X}=0$ - cathode membrane-CL interface; $\mathrm{X}=1$ - cathode GDL-CL interface; $\mathrm{Y}=0$-cathode gas outlet; $\mathrm{Y}=1$ - cathode gas inlet. 


\section{Figure 11}
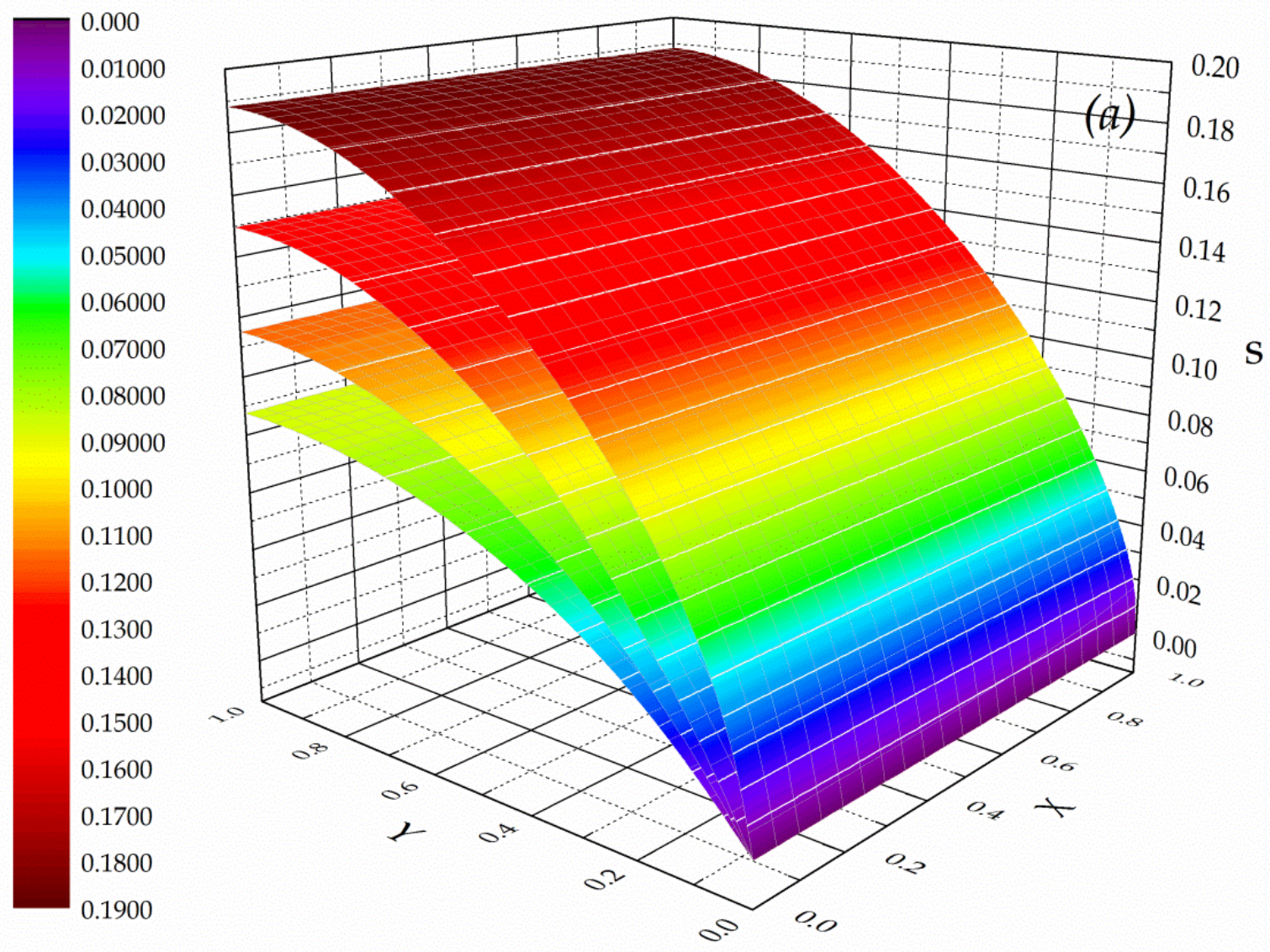

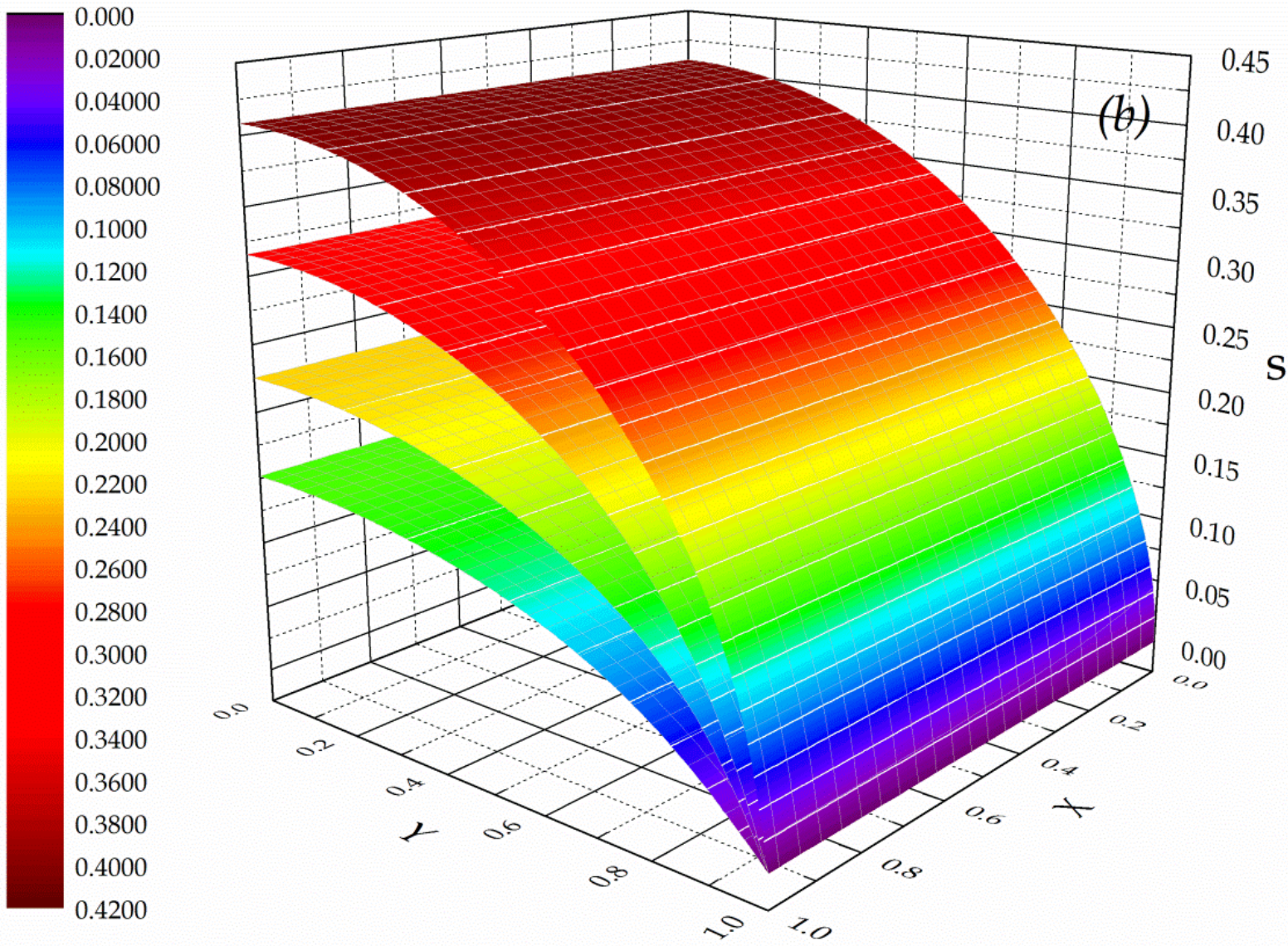

Fig. 11 Liquid water saturation in (a) anode channel and (b) cathode channel with various channel lengths at $0.3 \mathrm{~V}$ in base-case condition: $L=4.0,2.0,1.0$ and $0.5 \mathrm{~cm}$ from up down. $\mathrm{X}$ and $\mathrm{Y}$ are the dimensionless through-plane and in-plane directions. Boundaries $\mathrm{X}=0$ - anode channel outer boundary in Fig. 11a and cathode GDL-channel interface in Fig. 11b; X=1 - anode channel-GDL interface in Fig. 11a and cathode channel outer boundary in Fig. 11b; Y=0 - anode gas inlet in Fig. 11a and cathode gas outlet in Fig. 11b; Y=1 - anode gas outlet in Fig. 11a and cathode gas inlet in Fig. 11b. 


\section{Figure 12}

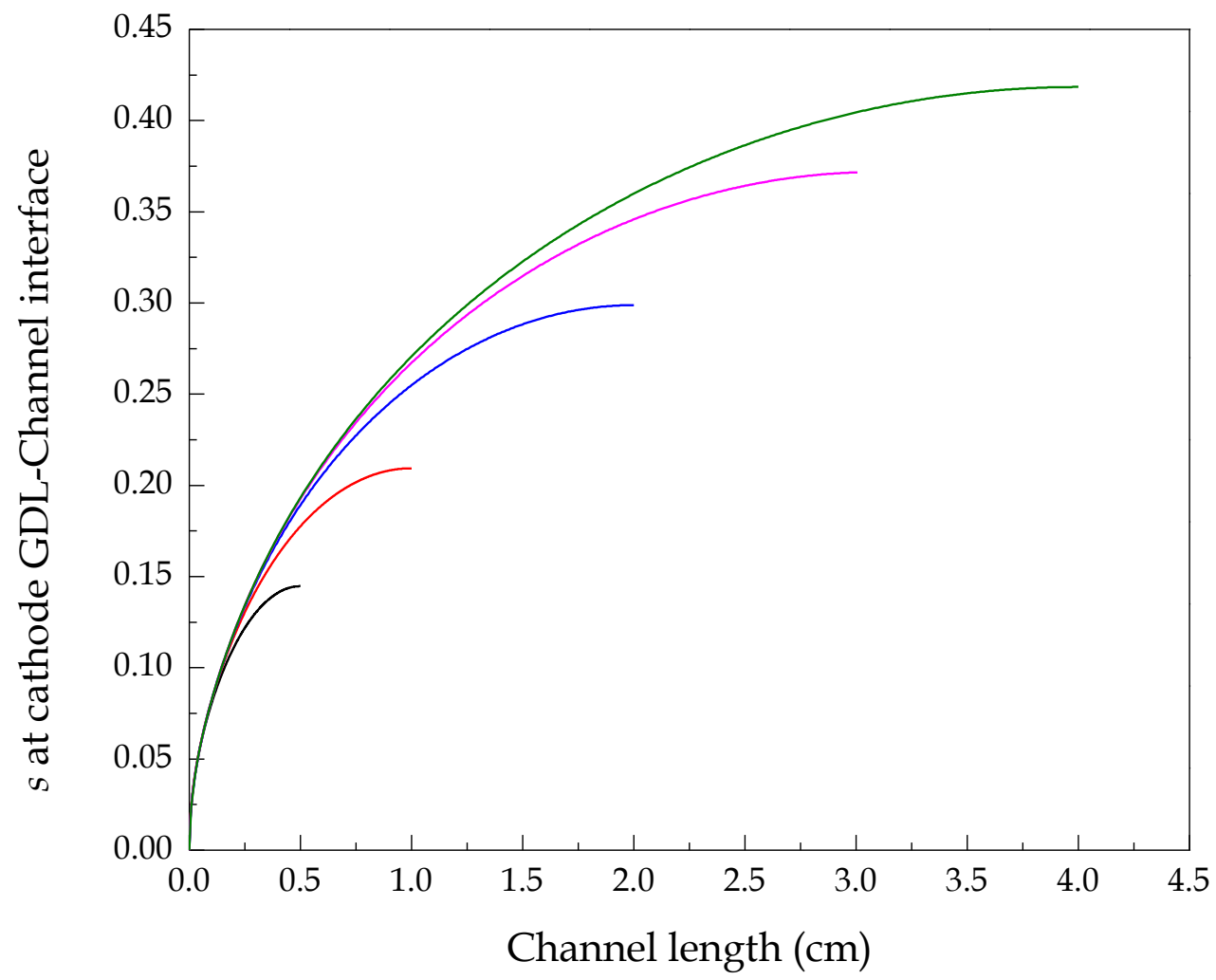

Fig. 12 Liquid water saturation at cathode GDL-channel interface at $0.3 \mathrm{~V}: \mathrm{X}=0$ is the cathode channel inlet, $\mathrm{X}=0.5,1.0,2.0,3.0$ and 4.0 is the outlet, respectively. 
Figure 13

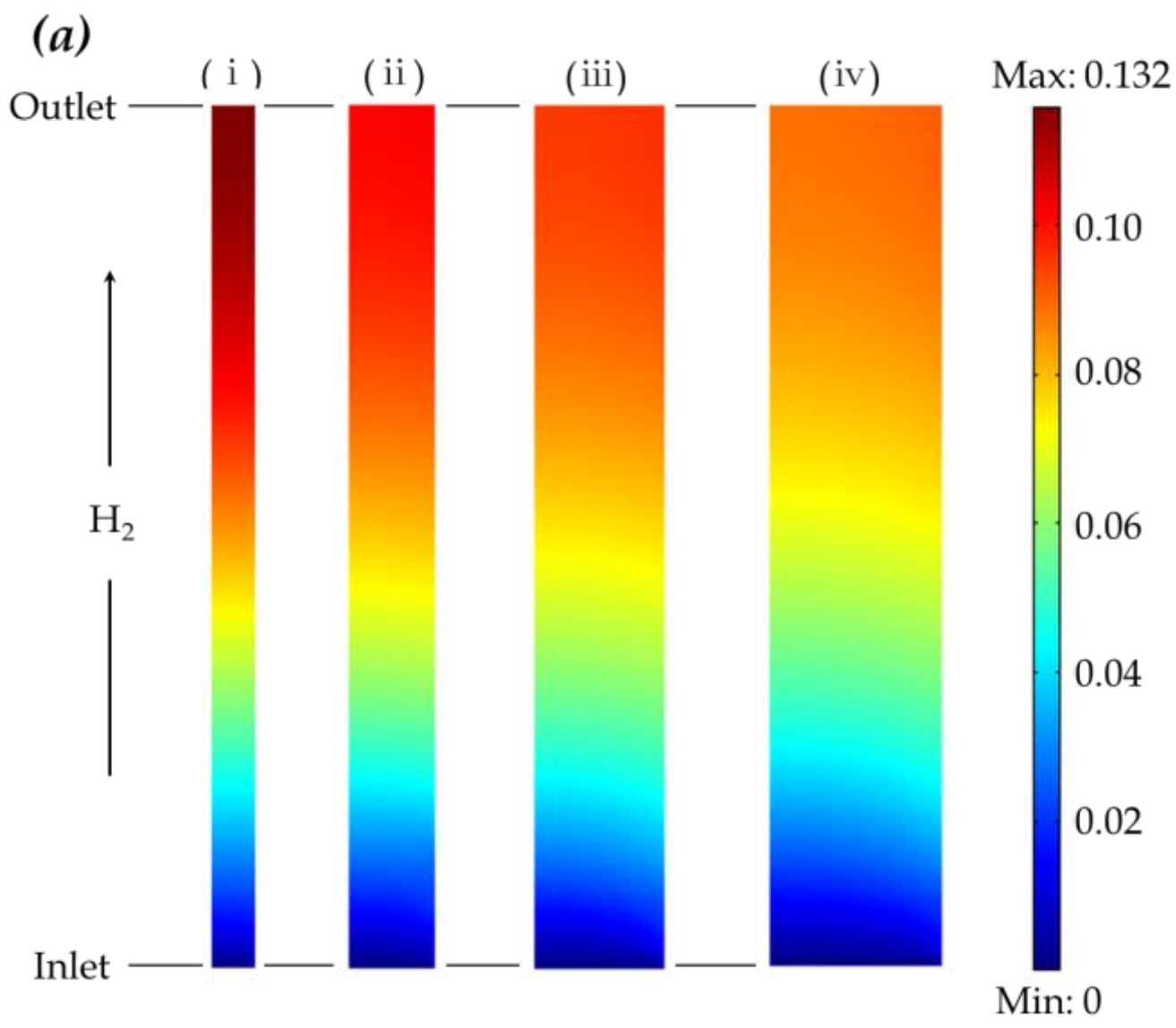




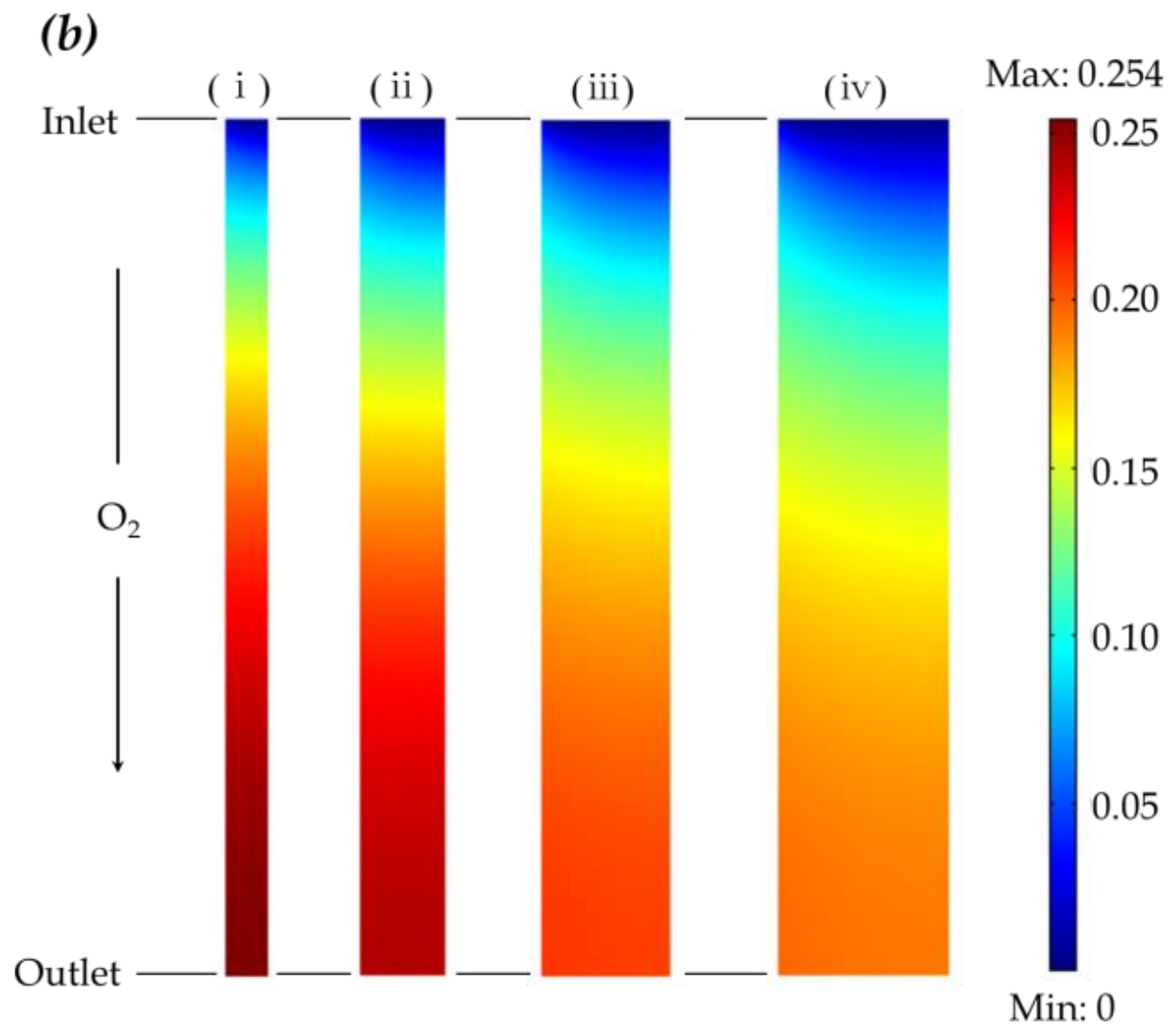

Fig. 13 Liquid water saturation in (a) anode channel and (b) cathode channel with various channel depth at $0.3 \mathrm{~V}$ in base-case condition: $\delta_{\mathrm{Ch}}=0.5,1.0,1.5$ and $2.0 \mathrm{~mm}$ from left to right. 


\section{Figure 14}
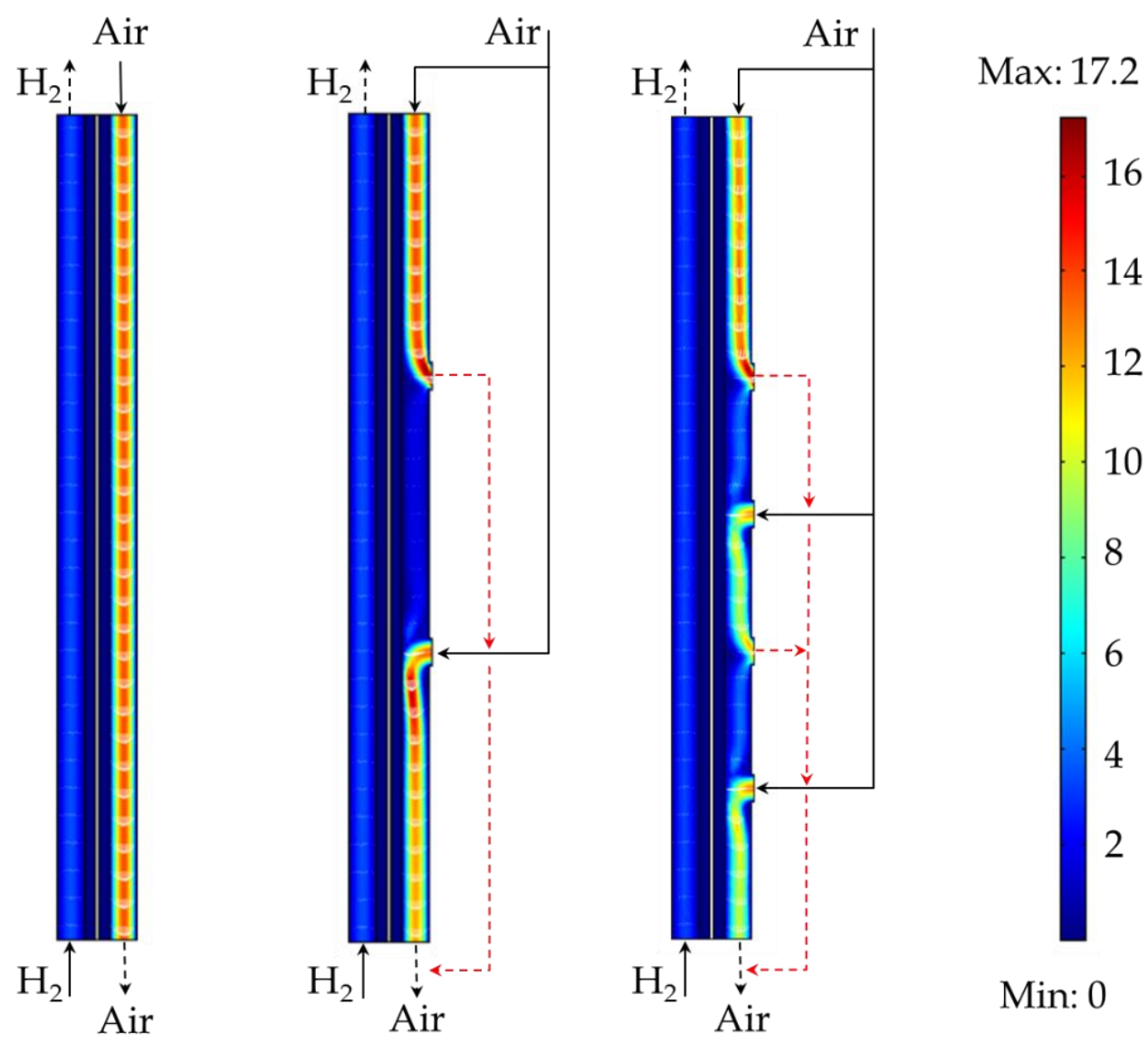

Fig. 14 Velocity magnitudes of reactant gases at $0.3 \mathrm{~V}$ of three channel designs in base-case condition 


\section{Figure 15}
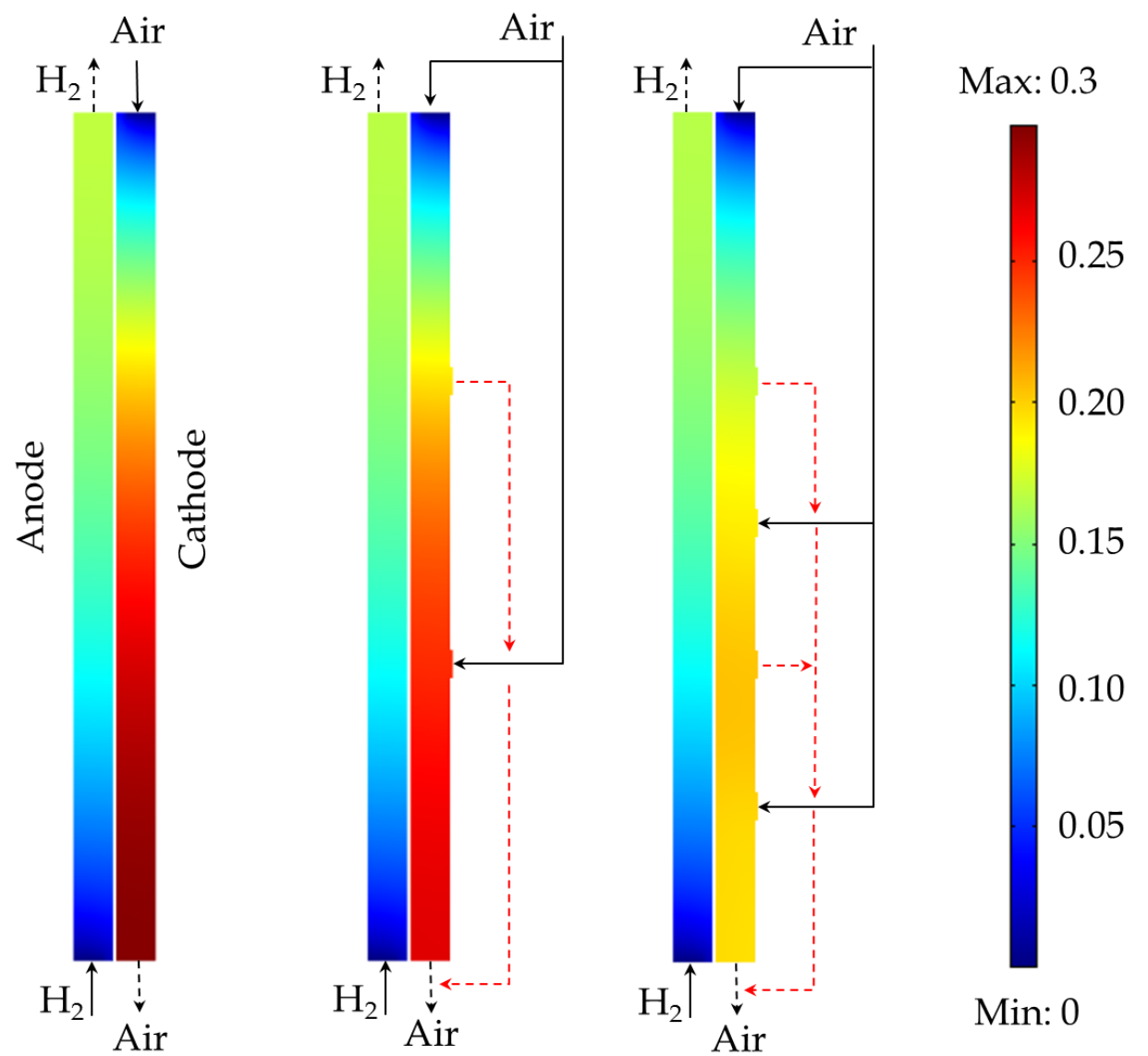

Fig. 15 Profiles of liquid water saturation of three channel designs at $1.2 \mathrm{~A} \mathrm{~cm}^{-2}$ in base-case condition 


\section{Figure 16}
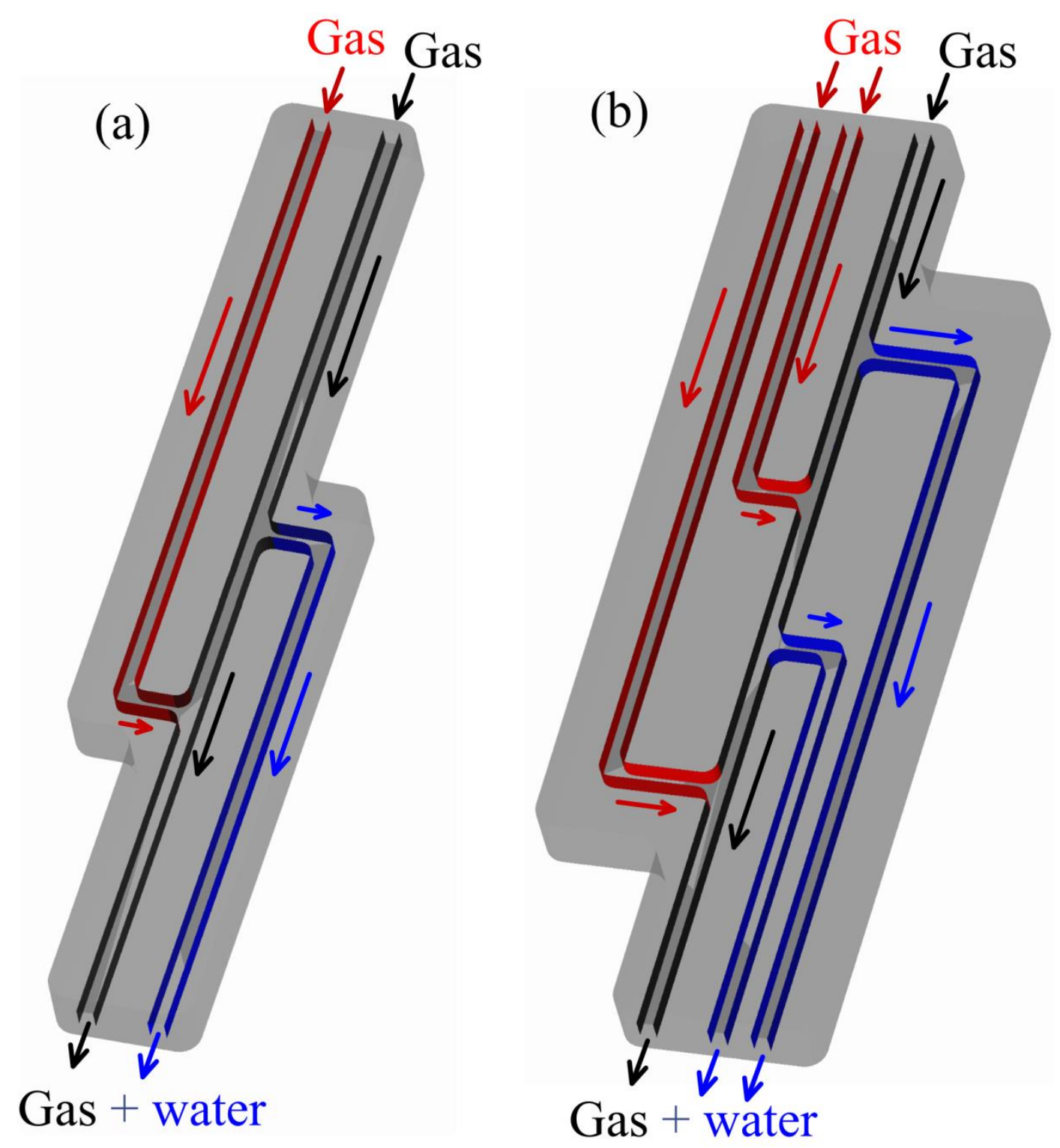

Fig. 16 Sketch of gas channel using multi- inlets and outlets design (a) double (b) triple 
Table 1 Structural parameters and material properties of the PEM fuel cells

\begin{tabular}{lllll}
\hline Parameters & Symbol & Unit & Value & Reference \\
\hline GDL conductivity & $\sigma_{G D L}$ & $\mathrm{~S} \mathrm{~m}^{-1}$ & 1250 & Sousa et al.; 2010 \\
GDL permeability & $k_{p, G D L}$ & $\mathrm{~m}^{2}$ & $4.97 \times 10^{-3}$ & Ismail et al.; 2012 \\
CL thickness & $\delta_{C L}$ & $\mu \mathrm{m}$ & 15 & Xing et al.; 2013a,b \\
CL permeability & $k_{p, C L}$ & $\mathrm{~m}^{2}$ & $4.97 \times 10^{-3}\left(\varepsilon_{C L} / \varepsilon_{G D L}\right)^{1.5}$ & Ismail et al.; 2012 \\
Membrane thickness & $\delta_{M}$ & $\mu \mathrm{m}$ & 120 & Xing et al.; 2013a,b \\
\hline
\end{tabular}


Table 2 Effective specific heat capacity and thermal conductivity of GDL, CL and channel

\begin{tabular}{|c|c|c|c|c|}
\hline & GDLs & CLs & Channels & Membrane \\
\hline$c_{p}^{e f f}$ & $\varepsilon_{G D L} c_{p, C}+s \varepsilon_{G D L} c_{p, w}^{l}+(1-s) \varepsilon_{G D L} c_{p}^{g}$ & $L_{P t} c_{p, P t}+\left(L_{C}+L_{S}\right) c_{p, C}+L_{M} c_{p, M}+s \varepsilon_{C L} c_{p, w}^{l}+(1-s) \varepsilon_{C L} c_{p}^{g}$ & $s c_{p, w}^{l}+(1-s) c_{p}^{g}$ & $c_{p, M}$ \\
\hline$k^{e f f}$ & $\varepsilon_{G D L} k_{C}+s \varepsilon_{G D L} k_{w}^{l}+(1-s) \varepsilon_{G D L} k^{g}$ & $L_{P_{t}} k_{P_{t}}+\left(L_{C}+L_{S}\right) k_{C}+L_{M} k_{M}+s \varepsilon_{C L} k_{w}^{l}+(1-s) \varepsilon_{C L} k^{g}$ & $s k_{w}^{l}+(1-s) k^{g}$ & $k_{M}$ \\
\hline
\end{tabular}


Table 3 Conservation of water in different phases and heat within different computational domain

\begin{tabular}{ccccc}
\hline & Channels & GDLs & CLs & Membrane \\
\hline Water vapour $S_{w}^{v}$ & $-S_{w}^{v l}$ & $-S_{w}^{v l}$ & $-S_{w}^{v d}-S_{w}^{v l}$ & - \\
Liquid water $S_{w}^{l}$ & $S_{w}^{v l}$ & $S_{w}^{v l}$ & $S_{w}^{d l}+S_{w}^{v l}$ & - \\
Dissolved water $S_{w}^{d}$ & 0 & 0 & $S_{w}^{r, i}+S_{w}^{v d}-S_{w}^{d l}$ & $S_{T}^{M}$ \\
\hline
\end{tabular}

Note: superscript $i$ represents the anode or cathode, the unit for each water source term is $\left(\mathrm{mol} \mathrm{m}^{-3} \mathrm{~s}^{-1}\right)$, for each heat source is $\left(\mathrm{W} \mathrm{m}^{-3}\right)$. 
Table 4 Source terms for mass and heat

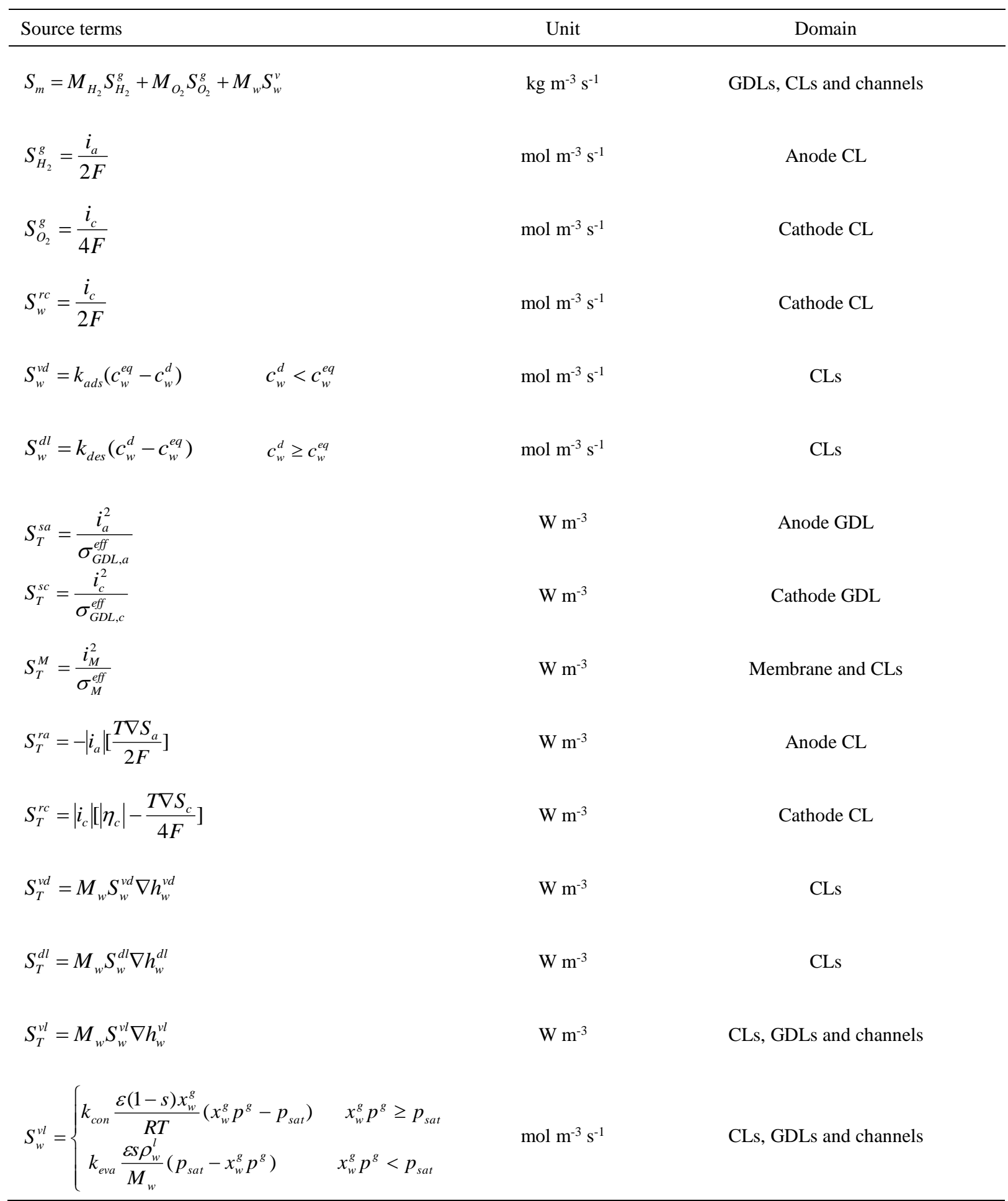


Table 5 Electrochemical parameters

\begin{tabular}{llll}
\hline Parameters & Anode & Cathode & References \\
\hline Charge transfer coefficient & $\alpha_{a}=0.5$ & $\alpha_{c}=0.7$ & Sun et al.; 2005 \\
Reference exchange current density $\left(\mathrm{A} \mathrm{cm}^{-2}\right)$ & $i_{0, a}^{\text {ref }}=1.0$ & $i_{0, c}^{\text {ref }}=10^{\left(3.507-\frac{4001}{T}\right)}$ & Marr and Li; 1999 \\
Equilibrium potential (V) & $\phi_{a}^{\text {eq }}=0$ & Eq. (16) & Ismail et al.; 2012 \\
Henry's constant $\left(\mathrm{Pa} \mathrm{m}^{3} \mathrm{~mol}^{-1}\right)$ & $H_{\mathrm{H}_{2}}=4.56 \times 10^{3}$ & $H_{O_{2}}=0.1 \mathrm{exp}\left(14.1-\frac{666}{T}\right)$ & Marr and Li; 1999 \\
$\mathrm{H}_{2} / \mathrm{O}_{2}$ reference concentration $\left(\mathrm{mol} \mathrm{cm}^{-3}\right)$ & $c_{\mathrm{H}_{2}}^{r e f}=5.64 \times 10^{-5}$ & $c_{O_{2}}^{r e f}=3.39 \times 10^{-6}$ & Bernardi and Verbrugge; 1992 \\
\hline
\end{tabular}


Table 6 Physical parameters

\begin{tabular}{|c|c|c|c|c|}
\hline Parameters & Symbol & Unit & Value & Reference \\
\hline Platinum density & $\rho_{P t}$ & $\mathrm{~kg} \mathrm{~m}^{-3}$ & $2.145 \times 10^{4}$ & Khajeh-Hosseini-Dalasm et al., 2010 \\
\hline Carbon density & $\rho_{C}$ & $\mathrm{~kg} \mathrm{~m}^{-3}$ & $1.8 \times 10^{3}$ & Khajeh-Hosseini-Dalasm et al., 2010 \\
\hline Liquid water density & $\rho_{w}^{l}$ & $\mathrm{~kg} \mathrm{~m}^{-3}$ & 988 & Yang et al., 2011 \\
\hline Dry membrane density & $\rho_{M}$ & $\mathrm{~kg} \mathrm{~m}^{-3}$ & $2.0 \times 10^{3}$ & Nguyen and White, 1993 \\
\hline Membrane equivalent weight & $E W$ & $\mathrm{~kg} \mathrm{~mol}^{-1}$ & 1.10 & Nguyen and White, 1993 \\
\hline Molar volume of water & $V_{W}$ & $\mathrm{~m}^{3} \mathrm{~mol}^{-1}$ & $1.8 \times 10^{-5}$ & Yi and Nguyen, 1998; Ge et al., 2005 \\
\hline Molar volume of dry membrane & $V_{M}$ & $\mathrm{~m}^{3} \mathrm{~mol}^{-1}$ & $5.5 \times 10^{-4}$ & Yi and Nguyen, 1998; Ge et al., 2005 \\
\hline Ionomer swelling coefficient & $k_{s}$ & - & $1.26 \times 10^{-2}$ & Shah et al., 2007 \\
\hline Liquid water viscosity at $293 \mathrm{~K}$ & $\mu_{w}^{l}$ & Pas & $1.002 \times 10^{-3}$ & Kestin et al., 1978 \\
\hline Surface tension of water & $\sigma$ & $\mathrm{N} \mathrm{m}^{-1}$ & $6.25 \times 10^{-2}$ & Pasaogullari and Wang, 2004b \\
\hline Condensation rate & $k_{c o n}$ & $\mathrm{~s}^{-1}$ & $1.0 \times 10^{2}$ & He et al., 2000 \\
\hline Evaporation rate & $k_{\text {eva }}$ & $\mathrm{atm}^{-1} \mathrm{~s}^{-1}$ & $1.0 \times 10^{2}$ & He et al., 2000 \\
\hline Entropy of hydrogen oxidation & $\nabla S_{a}$ & $\mathrm{~J} \mathrm{~mol}^{-1} \mathrm{~K}^{-1}$ & $1.612 \times 10^{2}$ & Lampinen and Fomino, 1993 \\
\hline Entropy of oxygen reduction & $\nabla S_{c}$ & $\mathrm{~J} \mathrm{~mol}^{-1} \mathrm{~K}^{-1}$ & $-3.24 \times 10^{2}$ & Lampinen and Fomino, 1993 \\
\hline Latent heat of membrane adsorption & $\nabla h_{w}^{v d}$ & $\mathrm{~J} \mathrm{~kg}^{-1}$ & $3.462 \times 10^{6}$ & Wu et al., 2010b \\
\hline Latent heat of membrane desorption & $\nabla h_{w}^{d l}$ & $\mathrm{~J} \mathrm{~kg}^{-1}$ & $3.462 \times 10^{6}$ & Wu et al., 2010b \\
\hline Latent heat of condensation/evaporation & $\nabla h_{w}^{v l}$ & $\mathrm{~J} \mathrm{~kg}^{-1}$ & $2.308 \times 10^{6}$ & Wu et al., 2010b \\
\hline
\end{tabular}


Table 7 Predicted current densities and computing time with various mesh characters

\begin{tabular}{cccccccc}
\hline & Channels & GDLs & CLs & Membrane & Total elements & $\begin{array}{c}i \text { at } 0.05 \mathrm{~V} \\
\left(\mathrm{~A} \mathrm{~cm}^{-2}\right)\end{array}$ & $\begin{array}{c}\text { Computing time } \\
(\mathrm{s})\end{array}$ \\
\hline Grid 1 & 10 & 10 & 10 & 10 & $2.1 \times 10^{4}$ & 2.02324 & 254 \\
Grid 2 & 30 & 10 & 10 & 10 & $3.3 \times 10^{4}$ & 2.02063 & 639 \\
Grid 3 & 50 & 10 & 10 & 10 & $4.5 \times 10^{4}$ & 2.01766 & 904 \\
Grid 4 & 50 & 30 & 10 & 10 & $5.7 \times 10^{4}$ & 2.01765 & 1134 \\
Grid 5 & 50 & 50 & 10 & 10 & $6.9 \times 10^{4}$ & 2.01764 & 1465 \\
Grid 6 & 50 & 50 & 30 & 10 & $8.1 \times 10^{4}$ & 2.01652 & 2082 \\
Grid 7 & 50 & 50 & 50 & 10 & $9.3 \times 10^{4}$ & 2.01641 & 2770 \\
Grid 8 & 50 & 50 & 50 & 50 & $1.05 \times 10^{5}$ & 2.01639 & 3092 \\
Grid 9 & 50 & 50 & 50 & 90 & $1.17 \times 10^{5}$ & 2.01639 & 3203 \\
\hline
\end{tabular}

Note: The number of elements along the channel is fixed at 300 . 
Table 8 Parameters used for model validation and base case condition in the study

\begin{tabular}{|c|c|c|c|c|}
\hline Symbol & Description (unit) & In-house & Wang et al., 2003 & Base case \\
\hline$\delta_{G D L}$ & GDL thickness (m) & $3.0 \times 10^{-4}$ & $3.0 \times 10^{-4}$ & $3.8 \times 10^{-4}$ \\
\hline$\delta_{C L}$ & CL thickness (m) & $1.5 \times 10^{-5}$ & $1.29 \times 10^{-5}$ & $1.5 \times 10^{-5}$ \\
\hline$\delta_{M}$ & Membrane thickness (m) & $5.5 \times 10^{-5}$ & $1.08 \times 10^{-4}$ & $1.2 \times 10^{-4}$ \\
\hline$\delta_{C h}$ & Flow channel depth (m) & $1.0 \times 10^{-3}$ & $1.0 \times 10^{-3}$ & $1.0 \times 10^{-3}$ \\
\hline$L$ & Channel length (m) & $1.0 \times 10^{-2}$ & $7.2 \times 10^{-2}$ & $1.0 \times 10^{-2}$ \\
\hline$\varepsilon_{G D L}$ & GDL porosity & 0.40 & 0.40 & 0.40 \\
\hline$m_{P t}$ & Platinum loading $\left(\mathrm{mg} \mathrm{cm}^{-2}\right)$ & $\begin{array}{c}0.10 \text { (anode) } \\
0.40 \text { (cathode) }\end{array}$ & 0.40 & 0.40 \\
\hline$f$ & $\mathrm{Pt} / \mathrm{C}$ mass ratio & $20 \%$ & $40 \%$ & $40 \%$ \\
\hline$L_{M}$ & Volume fraction of ionomer & $13.3 \%$ & $32.5 \%$ & $40 \%$ \\
\hline$\theta$ & Contact angel & $120^{\circ}$ & $120^{\circ}$ & $120^{\circ}$ \\
\hline$T$ & Operating temperature $\left({ }^{\circ} \mathrm{C}\right)$ & 80.0 & 70.0 & 70.0 \\
\hline$p$ & Operating pressure (atm) & 1.0 & 1.0 & 1.0 \\
\hline$R H$ & Relative humidity & $100 \%$ & $100 \%$ & $100 \%$ \\
\hline$\alpha_{c}$ & Cathode transfer coefficient & 0.6 & 2.0 & 0.7 \\
\hline$r_{a g g}$ & Agglomerate radius (m) & $1.0 \times 10^{-6}$ & $1.0 \times 10^{-6}$ & $1.0 \times 10^{-6}$ \\
\hline$\xi_{a}$ & Anode stoichiometric flow ratio & $11.8^{\mathrm{a}}$ & $1.8^{\mathrm{b}}$ & 1.2 \\
\hline$\xi_{c}$ & Cathode stoichiometric flow ratio & $12.4^{\mathrm{a}}$ & $1.4^{\mathrm{b}}$ & 2.0 \\
\hline
\end{tabular}

a: calculated at the volumetric flow ratio of 200 and $500 \mathrm{sccm}$ using Eq. (48) for anode and cathode, respectively, at in-house operation conditions; b: calculated at the volumetric flow ratio of 1200 and $2200 \mathrm{sccm}$ using Eq. (48) for anode and cathode, respectively, at given operation conditions in Wang et al. 2003. 
Table 9 Details of different levels of various study parameters and the predicted current densities at $0.05 \mathrm{~V}$

\begin{tabular}{ccccc}
\hline & Level 1 & Level 2 & Level 3 & Level 4 \\
\hline$m_{\mathrm{Pt}}\left(\mathrm{mg} \mathrm{cm}^{-2}\right)$ & 0.2 & 0.4 & 0.6 & 0.8 \\
$\varepsilon_{\mathrm{GDL}}(\%)$ & 20 & 40 & 60 & 80 \\
$\delta_{\mathrm{GDL}}(\mu \mathrm{m})$ & 60 & 200 & 260 & 380 \\
$\theta\left({ }^{\circ}\right)$ & 100 & 120 & 140 & 160 \\
$L(\mathrm{~cm})$ & 0.5 & 1.0 & 2.0 & 4.0 \\
$\delta_{\mathrm{Ch}}(\mathrm{mm})$ & 0.5 & 1.0 & 1.5 & 2.0 \\
\hline
\end{tabular}


Table 10 Predicted current densities with various levels of study parameters at different cell voltages

\begin{tabular}{|c|c|c|c|c|c|}
\hline \multirow{2}{*}{$\begin{array}{c}\text { Study } \\
\text { parameters }\end{array}$} & \multirow{2}{*}{ Cell voltage $(\mathrm{V})$} & \multicolumn{4}{|c|}{ Current densities $\left(\mathrm{A} \mathrm{cm}^{-2}\right)$ with different levels of study parameters } \\
\hline & & Level 1 & Level 2 & Level 3 & Level 4 \\
\hline \multirow{3}{*}{$m_{\mathrm{Pt}}$} & 0.7 & 0.0492 & 0.0547 & 0.0585 & 0.0585 \\
\hline & 0.5 & 0.592 & 0.598 & 0.575 & 0.487 \\
\hline & 0.3 & 1.382 & 1.357 & 1.294 & 1.123 \\
\hline \multirow{3}{*}{$\varepsilon \mathrm{GDL}$} & 0.7 & 0.0538 & 0.0547 & 0.0542 & 0.0535 \\
\hline & 0.5 & 0.488 & 0.598 & 0.627 & 0.639 \\
\hline & 0.3 & 0.821 & 1.357 & 1.523 & 1.593 \\
\hline \multirow{3}{*}{$\delta_{\mathrm{GDL}}$} & 0.7 & 0.0557 & 0.0553 & 0.0551 & 0.0547 \\
\hline & 0.5 & 0.664 & 0.635 & 0.623 & 0.598 \\
\hline & 0.3 & 1.686 & 1.554 & 1.497 & 1.357 \\
\hline \multirow{3}{*}{$\theta$} & 0.7 & 0.0546 & 0.0547 & 0.0547 & 0.0547 \\
\hline & 0.5 & 0.596 & 0.598 & 0.599 & 0.599 \\
\hline & 0.3 & 1.334 & 1.357 & 1.364 & 1.367 \\
\hline \multirow{3}{*}{$L$} & 0.7 & 0.0546 & 0.0547 & 0.0547 & 0.0547 \\
\hline & 0.5 & 0.595 & 0.598 & 0.598 & 0.597 \\
\hline & 0.3 & 1.349 & 1.357 & 1.337 & 1.301 \\
\hline \multirow{3}{*}{$\delta_{\mathrm{Ch}}$} & 0.7 & 0.0547 & 0.0547 & 0.0546 & 0.0545 \\
\hline & 0.5 & 0.601 & 0.598 & 0.594 & 0.590 \\
\hline & 0.3 & 1.371 & 1.357 & 1.337 & 1.318 \\
\hline
\end{tabular}

Note: when investigating the study parameter, others are fixed at constants in base-case condition in Table 8 . 